\title{
BALANÇO DA PRODUÇÃO CIENTÍFICA SOBRE A POLÍTICA NACIONAL DE EDUCAÇÃO ESPECIAL NA PERSPECTIVA DA EDUCAÇÃO INCLUSIVA (2010-2020)
}

\author{
LUANA LEAL RIBEIRO ${ }^{1}$ \\ ORCID: http://orcid.org/0000-0002-6710-0167 \\ RENATA MALDONADO DA SILVA ${ }^{2}$ \\ ORCID: http://orcid.org/0000-0001-7901-623X \\ SILVIA ALICIA MARTÍNEZ \\ ORCID: https://orcid.org/0000-0001-9612-6924
}

\begin{abstract}
RESUMO: A partir da publicação da Política Nacional de Educação Especial na Perspectiva da Educação Inclusiva (PNEEPEI) no ano de 2008, verificou-se a expansão do setor público no que se refere à oferta de serviços educacionais aos alunos público-alvo da Educação Especial (PAEE), baseandose na necessidade do estabelecimento de sistemas educacionais inclusivos. Nesse sentido, o lócus da oferta da Educação Especial deveria ser o Atendimento Educacional Especializado oferecido nas escolas regulares, intensificando o investimento de recursos públicos na implementação desses espaços. Porém, no ano de 2017, iniciou-se uma série de discussões com o objetivo de promover a revisão e atualização da PNEEPEI, sob o argumento de que pesquisadores e grupos de pesquisa apontavam diversas críticas com relação à chamada política de educação inclusiva. A minuta com a proposta de atualização divulgada em 2018 estabelecia a possibilidade da oferta de serviços educacionais aos alunos PAEE em classes e escolas especiais, historicamente gerenciadas por instituições privado-assistenciais no País. Destarte, com base na realização de um balanço da produção científica publicado por pesquisadores da área entre os anos de 2010 e 2020, busca-se identificar as principais críticas, positivas e negativas, conferidas à PNEEPEI que possam justificar a necessidade da atualização proposta pelo Ministério da Educação (MEC). Para tal, foram utilizados os descritores "política nacional" e "educação especial" nos portais de busca de Periódicos da CAPES, no portal Scielo e no Google Acadêmico, sendo então selecionados e analisados 20 trabalhos que indicavam contemplar o objetivo aventado pelo presente artigo. A partir das análises realizadas, identificou-se que, na literatura científica, as críticas negativas foram parcialmente incorporadas ao novo texto da política divulgado em setembro de 2020, ao mesmo tempo que as críticas positivas com relação à PNEEPEI foram ignoradas no novo documento.
\end{abstract}

\footnotetext{
${ }^{1}$ Doutoranda do Programa de Pós-Graduação em Políticas Sociais da Universidade Estadual do Norte Fluminense Darcy Ribeiro (UENF). Campos dos Goytacazes, RJ, Brasil. <luanalealr@hotmail.com>

2 Professora Associada da Universidade Estadual do Norte Fluminense Darcy Ribeiro (UENF). Campos dos Goytacazes, RJ, Brasil.<r.maldonado@globo.com>

${ }^{3}$ Professora Associada da Universidade Estadual do Norte Fluminense Darcy Ribeiro (UENF). Campos dos Goytacazes, Rio de Janeiro (RJ), Brasil. <silvia-martinez@hotmail.com> 
Palavras-chave: Educação Especial, Política Nacional de Educação Especial, Educação Inclusiva.

\title{
BALANCE OF THE SCIENTIFIC PRODUCTION ON THE NATIONAL POLICY OF SPECIAL EDUCATION IN THE PERSPECTIVE OF INCLUSIVE EDUCATION (2010-2020)
}

\begin{abstract}
Since the publication of the National Policy on Special Education from the Perspective of Inclusive Education (PNEEPEI) in 2008, there has been an expansion of the public sector regarding the provision of educational services to students targeted for Special Education (PAEE), based on the need to establish inclusive educational systems. In this sense, the locus of Special Education should be the Specialized Education Service offered in regular schools, intensifying the investment of public resources in the implementation of these spaces. However, in 2017, a series of discussions began with the aim of promoting the revision and updating of PNEEPEI, on the grounds that researchers and research groups pointed out several criticisms regarding the so-called inclusive education policy. The draft with the update proposal released in 2018 established the possibility of offering educational services to PAEE students in special classes and schools, historically managed by private-assistance institutions in the country. Thus, based on the realization of a balance of the scientific production published by researchers in the area between the years 2010 and 2020, we seek to identify the main criticisms, positive and negative, conferred to PNEEPEI that can justify the need for the update proposed by the Ministry of Education (MEC). To this end, we used the descriptors "national policy" and "special education" in the search portals of CAPES Periodicals, Scielo and Google Academic, being then selected and analyzed 20 papers that indicated contemplating the objective of this article. From the analysis, it was identified that, in the scientific literature, the negative criticisms were partially incorporated into the new text of the policy released in September 2020, while the positive criticisms regarding PNEEPEI were ignored in the new document.
\end{abstract}

Keywords: Special Education, National Policy for Special Education, Inclusive Education.

\section{BALANCE DE LA PRODUCCIÓN CIENTÍFICA ACERCA DE LA POLÍTICA NACIONAL DE EDUCACIÓN ESPECIAL DESDE LA PERSPECTIVA DE LA EDUCACIÓN INCLUSIVA (2010 - 2020)}

RESUMEN: Con la publicación de la Política Nacional de Educación Especial en la Perspectiva de la Educación Inclusiva (PNEEPEI), en 2008, se produjo una expansión del sector público de prestación de servicios educativos a los estudiantes destinatarios de Educación Especial (PAEE), a partir del argumento de la necesidad de establecer sistemas educativos inclusivos. En consecuencia, el locus de la oferta de Educación Especial debe ser el Servicio Educativo Especializado que se ofrece en las escuelas regulares, intensificando la inversión de recursos públicos para la implementación de estos espacios. Sin embargo, en 2017 se inició una serie de discusiones con el objetivo de promover la revisión y actualización del PNEEPEI, con el argumento de que investigadores y grupos de investigación habían realizado varias críticas a la llamada "política de educación inclusiva". La propuesta de actualización presentada en 2018 estableció la posibilidad de ofrecer servicios educativos a los estudiantes PAEE en clases especiales y escuelas históricamente gestionadas por instituciones de bienestar privadas en el país. Así, a partir de la realización de un balance de la producción científica publicada entre los años 2010 y 2020, buscamos identificar las principales críticas, positivas y negativas, efectuadas al PNEEPEI que puedan justificar la necesidad de la actualización que plantea el Ministerio de Educación (MEC). Para ello, se utilizaron los descriptores "política nacional" y "educación especial" en los portales de búsqueda de Revistas de CAPES, el portal Scielo y Google Scholar, y se seleccionaron y analizaron 20 trabajos que contemplaban el objetivo propuesto por este artículo. A partir de los análisis realizados en la literatura científica, se identificó que las críticas negativas se incorporaron parcialmente al nuevo texto de política difundido en septiembre de 2020, mientras que las críticas positivas al PNEEPEI fueron ignoradas en el nuevo documento. 
Palabras clave: Educación Especial, Política Nacional de Educación Especial, Educación Inclusiva. 


\section{INTRODUÇÃO}

No Brasil, historicamente, as políticas sociais e educacionais inclusivas foram inicialmente desenvolvidas de forma focalizada, ao se delegar às instituições privadas o papel, ainda que de forma parcial, do seu cumprimento. Porém, esse quadro foi modificado principalmente durante a gestão do Partido dos Trabalhadores - PT (2003-2016), uma vez que a inclusão se tornou uma das principais metas das políticas educacionais brasileiras. O projeto social-liberal ${ }^{4}$, vigente durante a gestão PT, endossava a articulação entre as esferas social e econômica, especialmente a partir do discurso sobre a necessidade de se estabelecer a inclusão social, na qual o acesso à educação era um elemento estratégico. Especificamente sobre a Educação Especial, equivocadamente associada quase que com exclusividade às políticas educacionais inclusivas, é preciso destacar que ela passou a ser disputada por diferentes correlações de forças existentes na sociedade, em relação à responsabilidade pela prestação dos serviços ${ }^{5}$ aos alunos público-alvo dessa modalidade.

No plano discursivo, apesar de o Estado se apresentar como protagonista nos mecanismos que buscavam a ampliação da cidadania, verificou-se a ampla participação de organizações privadas na oferta de serviços educacionais, inclusive voltados para a Educação Especial, ao se instituir a possibilidade do estabelecimento de convênios entre o Estado e as instituições privadas sem fins lucrativos na oferta dos "serviços" educacionais para essa modalidade. Entretanto, no ano de 2008, foi lançada a Política Nacional de Educação Especial na Perspectiva da Educação Inclusiva - PNEEPEI, considerada como uma das principais referências no âmbito da Educação Especial no Brasil.

Esse documento apresenta como objetivo assegurar a inclusão escolar dos alunos públicoalvo da Educação Especial (PAEE), a partir da orientação de que os sistemas de ensino deveriam garantir acesso à escola regular, com participação, aprendizagem e continuidade nos níveis mais elevados do ensino, assim como assegurar a transversalidade da modalidade da Educação Especial, que deveria ser ofertada desde a educação infantil até a educação superior. São descritos como PAEE os alunos com deficiência, que apresentam impedimentos de longo prazo de natureza física, mental, intelectual ou sensorial; os que possuem transtornos globais de desenvolvimento que apresentam alterações qualitativas das interações sociais recíprocas e na comunicação; e os alunos com altas habilidades/superdotação, que demonstram potencial elevado nas áreas intelectual, acadêmica, de liderança, psicomotricidade e/ou artes (BRASIL, 2008).

A PNEEPEI anunciava, expressamente, uma crítica contundente em relação à organização de escolas e classes especiais, que funcionavam, em sua maioria, por meio de entidades privadoassistenciais, sob o discurso da necessidade do estabelecimento de sistemas educacionais inclusivos. Portanto, a PNEEPEI defendia uma proposta que se opunha à segregação dos alunos público-alvo dessa modalidade nesses espaços. Contudo, o estabelecimento de parcerias público-privadas e a possibilidade da oferta de serviços especializados em classes/escolas segregadas no âmbito da Educação Especial voltaram a ser fortemente impulsionados principalmente após o processo de conclusão do impeachment da presidente Dilma Rousseff.

Nesse contexto, a partir de 2017, emergiram discussões sobre a necessidade de atualização da PNEEPEI. Embora vários pesquisadores da Educação Especial tenham denunciado os limites e problemas decorrentes da PNEEPEI, foi construído um relativo consenso de que o lócus de atendimento dos alunos público-alvo dessa modalidade deveria ocorrer nas classes regulares de ensino nas instituições escolares. As críticas sobre como a PNEEPEI foi sendo implementada, com destaque para a restrição da modalidade da Educação Especial na oferta do Atendimento Educacional Especializado - AEE - nas Salas de Recursos Multifuncionais - SRM - nas escolas regulares, vêm sendo utilizadas como argumento para legitimar a necessidade da atualização da referida política.

\footnotetext{
4 “Em termos políticos, o social-liberalismo, ao se guiar pelo conceito de equidade social, defende a promoção da igualdade de oportunidades entre os indivíduos via a educação. A educação, antes uma forma de emancipação humana, fica, de acordo com essa perspectiva, inteiramente subordinada aos requisitos de habilidades necessárias aos processos de produção de mercadorias comandado pelo capital" (CASTELO, 2011, p. 261).

${ }^{5}$ Em análise dos discursos disseminados pelas organizações internacionais, Garcia (2017, p. 22) identificou que "a educação é afirmada como um 'serviço', em ofensiva à defesa desse e de outros direitos sociais, mediante a compreensão de que pode ser ofertada pelos setores privados da sociedade por meio de um contrato de gestão estabelecido com o Estado".

Educação em Revista|Belo Horizonte|v.37|e26361|2021
} 
O AEE é descrito na PNEEPEI como um serviço cuja finalidade seria identificar, elaborar e organizar recursos pedagógicos e de acessibilidade com vistas a eliminar as barreiras para a plena participação dos alunos, conforme as suas necessidades específicas. Nesse contexto, as atividades desenvolvidas no AEE seriam diferenciadas das realizadas na sala de aula comum, ou seja, não poderiam substituir a escolarização nas escolas regulares, sendo, então, suplementares e/ou complementares à formação do aluno (BRASIL, 2008). Como forma de apoiar a organização e a oferta do AEE aos alunos PAEE matriculados nas classes comuns do ensino regular, as SRMs constituem-se como espaços físicos que disponibilizam equipamentos de informática, mobiliários, materiais pedagógicos e de acessibilidade, com o objetivo de assegurar a esses alunos condições de acesso, participação e aprendizagem (BRASIl, 2010).

O termo AEE aparece na legislação brasileira atrelado à ideia de que os estudantes PAEE deveriam ser escolarizados preferencialmente na escola comum, utilizando-se do apoio de serviços educacionais especializados, pois, de acordo com Mendes (2019), a escolarização exclusiva desses sujeitos nas classes comuns seria insuficiente para responder as necessidades educacionais diferenciadas desses alunos. Estudos desenvolvidos pelo Observatório Nacional de Educação Especial (ONEESP) indicaram que a concepção de AEE descrita na PNEEPEI precisava ser superada, uma vez que se apresentava como um

\begin{abstract}
1) Serviço de apoio baseado exclusivamente no AEE ofertado em SRM que tem se transformado no lócus de acomodação da diferença na escola e ainda centra a deficiência no aluno e no seu atendimento, provocando pouco ou nenhum impacto na classe comum ou na escola que precisa mudar para oferecer ensino de qualidade para todos e não apenas para o PAEE; 2) Além de ser uma medida conservadora, pois mantém o status quo da escola pública com seus indicadores de baixa qualidade, a adoção deste serviço, enquanto modelo tamanho único, não respondia satisfatoriamente às necessidades educacionais do conjunto dos estudantes do PAEE; e 3) Política de caráter remediativo ao priorizar intervir na faixa de escolaridade obrigatória (atualmente definida dos quatro aos 17 anos), negligenciando a possibilidade de intervir preventivamente com programas de educação precoce, essencial para o PAEE (MENDES, 2019, p. 14).
\end{abstract}

A mesma autora afirma que, por meio dessas pesquisas, ainda foi possível identificar que nem sempre os dispositivos legais conseguiam ser implementados na prática, pois os municípios apresentavam diferentes histórias de organização de serviços de apoio à inclusão escolar com a disponibilização de múltiplos serviços especializados ${ }^{6}$. Assim, ainda destaca que, por meio das pesquisas realizadas pelo Observatório, constatou-se a existência de movimentos diversos de cada município com relação à padronização da política de inclusão escolar com a oferta de AEE por meio das SRMs (MENDES, 2019).

Nesse contexto, a tensão acerca da responsabilidade sobre a prestação dos serviços educacionais aos alunos PAEE é acentuada, principalmente a partir do momento em que o Censo Escolar brasileiro identificou um aumento contínuo e expressivo de matrículas do PAEE nas escolas comuns. Consequentemente, ocorreu uma diminuição gradual das matrículas em classes especiais, em instituições especializadas e em escolas privadas (MENDES, 2019), surgindo o debate sobre a

a definição do papel das instituições especializadas nas políticas públicas de educação inclusiva, desde propostas mais radicais que defendem sua extinção para impedir a segregação escolar, passando por outras mais conciliadoras que defendem sua reconfiguração como serviço de apoio à escolarização inclusiva, até outras mais conservadoras que apostam em sua manutenção (MENDES, 2019, p. 6-7).

Considerando que, no ano de 2018, surgiu a proposta de revisão e atualização da PNEEPEI sob o argumento principal da necessidade de ampliação dos serviços educacionais especializados aos

\footnotetext{
${ }^{6}$ Mendes (2019, p. 15) destaca que foram encontrados modelos baseados em serviços diversos, como salas de apoio/reforço, classes especiais, regime de colaboração entre professores especializados e do ensino comum, serviços itinerantes, auxílio de profissionais de apoio e, apenas mais recentemente, os modelos de apoio preferencial em SRM, conforme recomendava o MEC.
} 
alunos PAEE, o presente trabalho busca investigar as produções acadêmicas científicas publicadas no período de 2010-2020 em periódicos e livros que tiveram como objeto de análise a PNEEPEI. O objetivo de construir este balanço de produção ancora-se na necessidade de compreender como pesquisadores da área analisam essa política e, em certa medida, considerando que os trabalhos selecionados representam parte da produção publicada, as possíveis influências que tais produções incidiram na delimitação da nova Política Nacional de Educação Especial: Equitativa, Inclusiva e com Aprendizado ao Longo da Vida, divulgada em 30 de setembro de 2020. Buscando atingir esse objetivo, primeiramente serão apresentados os procedimentos metodológicos utilizados no trabalho, com o propósito de descrever o percurso utilizado na condução do balanço de produção, com relação à busca e seleção do material. Posteriormente, com base nos textos selecionados e analisados, serão indicadas as categorias criadas para a descrição dos principais pontos apresentados pelos autores com relação à PNEEPEI.

\section{PROCEDIMENTOS METODOLÓGICOS}

O referencial metodológico adotado no presente estudo insere-se na perspectiva da abordagem quanti-qualitativa, pois se utiliza tanto da técnica da quantificação na etapa da seleção dos materiais que serão analisados quanto do tratamento qualitativo das abordagens que os autores dos trabalhos selecionados apresentaram com relação à análise da PNEEPEI. Minayo e Sanches (1993) descrevem os estudos quantitativos como os que possuem características mais objetivas de quantificação dos fenômenos, enquanto os estudos qualitativos possuem um enfoque no social e na compreensão da subjetividade. É nesse sentido que os autores apontam a possibilidade de utilização da combinação das duas abordagens, uma vez que, "do ponto de vista metodológico, não há contradição, assim como não há continuidade, entre investigação quantitativa e qualitativa. Ambas são de natureza diferente. [...] Assim, o estudo quantitativo pode gerar questões para serem aprofundadas qualitativamente, e viceversa" (MINAYO; SANCHES, 1993, p. 247). Dessa forma, a análise dos dados coletados para o desenvolvimento deste estudo permitiu a realização de um balanço quanti-qualitativo de trabalhos científicos que discorrem especificamente sobre a PNEEPEI.

A opção pelo balanço de produções científicas como procedimento metodológico justificase por permitir que o pesquisador possa compreender, com base nos trabalhos publicados, em que medida esse tema vem sendo pesquisado, bem como em quais meios de divulgação são apresentados. Também possibilita identificar se há concentração de publicações sobre o tema em determinados periódicos ou se os trabalhos são desenvolvidos por autores vinculados a uma mesma Instituição de Ensino Superior (IES). Destarte, neste item será apresentado o resultado do balanço das produções divulgadas em periódicos e livros, sendo então organizado em duas partes: inicialmente, será exposto o processo de busca e seleção dos trabalhos, com a descrição metodológica das etapas que foram desenvolvidas para alcance das pesquisas que foram posteriormente analisadas; já na segunda parte, será realizado um breve perfil com o detalhamento dos dados quantitativos levantados em relação aos trabalhos que foram selecionados para análise.

Pintassilgo e Beato (2017, p. 48) destacam que os balanços de produção são "um exercício de absoluta necessidade para qualquer campo de pesquisa que aspire a um estatuto de cientificidade", sendo, então, uma atividade fundamental para avaliar a qualidade dos trabalhos, assim como para delinear futuros percursos da pesquisa. Nesse sentido, o balanço de produção ainda pode ser considerado como um relevante procedimento inicial no processo de pesquisa científica, colaborando com a familiarização e seleção de produções que podem subsidiar, futuramente, novas pesquisas. Portanto, essa opção metodológica permite que os pesquisadores consigam obter conhecimentos acerca das produções científicas que são divulgadas no meio acadêmico sobre uma determinada problemática que está sendo investigada (MOCHEUTI, 2017).

Destaca-se que o caminho metodológico percorrido no desenvolvimento desse balanço de produção se ancora em dois níveis de pesquisa: inicialmente, foi realizada uma pesquisa exploratória, que, de acordo com Gil (2008), é executada com a finalidade de proporcionar uma visão geral, de tipo aproximativo, sobre um determinado fato, sendo, geralmente, a primeira etapa de uma investigação mais ampla; e o segundo nível é o que Gil (2008) aponta como pesquisa descritiva, que, a partir de seus objetivos, acaba proporcionando uma nova visão sobre o problema pesquisado, aproximando-se, assim, 
das pesquisas exploratórias. Cabe destacar que o caráter "exploratório" deste trabalho se relaciona ao processo de busca e levantamento das pesquisas existentes que privilegiaram a análise da Política Nacional de Educação Especial na Perspectiva da Educação Inclusiva (PNEEPEI) entre os anos de 2010 e 2020. Em seguida, serão descritas as informações coletadas nos trabalhos integralmente analisados e que mantêm relação de aproximação com a problemática que está sendo investigada.

\section{Processo de busca e seleção dos trabalhos}

Com o objetivo de identificar trabalhos que propuseram como objeto de análise a Política Nacional de Educação Especial na Perspectiva da Educação Inclusiva (PNEEPEI), inicialmente foram elencados o Portal de Periódicos da Coordenação de Aperfeiçoamento de Pessoal de Nível Superior (CAPES), o portal de periódicos da Scientific Electronic Library Online (SciELO) e o portal de buscas Google Acadêmico. A pesquisa foi realizada nas três plataformas no dia 8 de setembro de $2020 \mathrm{com}$ a utilização dos descritores "política nacional" e "educação especial", para selecionar os trabalhos que seriam posteriormente analisados. A escolha desses descritores baseia-se na necessidade de serem identificados os trabalhos que abarcassem exatamente a análise da PNEEPEI. Portanto, partiu-se do pressuposto de que a utilização dos termos anteriormente citados contemplariam, necessariamente, as produções acadêmicas voltadas exclusivamente para a análise da refererida política. Este percurso teóricometodológico inicial encaminhou este estudo para a seguinte questão de pesquisa: como a PNEEPEI vem sendo apropriada na produção acadêmica no campo da educação especial e quais as possíveis influências que os trabalhos produzidos neste âmbito exerceram na delimitação da proposta de atualização e revisão da referida política?

Como marco temporal, delimitou-se a busca para os anos de 2010 a 2020. Cabe destacar que, por conta das características de cada portal, houve a necessidade de modificar o processo de busca, apesar de ter sido possível a utilização dos mesmos descritores em todos os portais, sendo esse processo, assim como o fluxo de pesquisa, descritos a seguir.

Primeiramente, foi consultado o portal de periódicos da CAPES, sendo utilizados os seguintes filtros de busca avançada: os termos exatos "política nacional” e “educação especial” deveriam ser buscados em "qualquer" índice, ou seja, poderiam aparecer no título, resumo e/ ou no corpo do texto. O marco temporal foi delimitado para os últimos dez anos, e optou-se pela procura somente de artigos, em qualquer idioma. Após essa delimitação, foram encontrados 153 trabalhos, sendo 14 selecionados e 135 descartados. Num segundo momento, no portal SciELO - modalidade de busca avançada -, foram descritos os termos exatos "política nacional" e "educação especial", que também poderiam estar localizados em todos os índices, ou seja, a busca dos termos poderia acontecer no nome do periódico, título e/ou resumos dos trabalhos. A busca nesse portal resultou em 20 artigos encontrados, com o quantitativo de 9 selecionados e 11 descartados.

Como terceiro passo, a utilização dos mesmos descritores no Google Acadêmico resultou em um quantitativo de 16.100 trabalhos na primeira tentativa de busca. Com o objetivo de promover um recorte na pesquisa, na segunda tentativa foi utilizado o termo "política nacional de educação especial", apresentando 11.900 trabalhos. Em função de este número ainda ser expressivamente amplo e pela impossibilidade de análise de todos esses achados, optou-se pela busca de trabalhos que possuíam os termos exatos "política nacional" e "educação especial", obrigatoriamente no título. Essa seleção gerou o quantitativo de 53 resultados, sendo 10 selecionados e 43 descartados. Assim, no total, foram encontrados 226 trabalhos, sendo 33 selecionados e 189 descartados, como será apresentado na tabela a seguir:

Tabela 1 - Quantitativo de trabalhos localizados, descartados e selecionados, distribuídos por portal

\begin{tabular}{lccc}
\multicolumn{1}{c}{ Portal } & Encontrados & Descartados & Selecionados \\
\hline Periódicos CAPES & 153 & 135 & 14 \\
\hline SciELO & 20 & 11 & 9 \\
\hline Google Acadêmico & 53 & 43 & 10 \\
\hline Total & 226 & 189 & 33 \\
\hline
\end{tabular}

Fonte: Elaboração própria com base nos trabalhos encontrados nos portais da Capes, Google Acadêmico e SciELO. 
$\mathrm{Na}$ etapa de seleção dos trabalhos que seriam posteriormente analisados, optou-se pelo critério de avaliação dos títulos, dos resumos e das palavras-chave dos artigos que foram identificados, a fim de verificar quais contemplavam, ainda que parcialmente, a análise da PNEEPEI/2008. Entretanto, um expressivo quantitativo de artigos citava a referida política no título e/ou resumo, mas não efetivava a sua análise, sendo esses trabalhos descartados. Assim, nessa etapa de seleção, foram desconsiderados os trabalhos que anunciavam de alguma forma a PNEEPEI/2008, mas não a analisavam propriamente. O gráfico abaixo apresenta o quantitativo de trabalhos que foram eliminados, considerando seu ano de publicação, podendo ser identificado o predomínio de artigos que foram publicados e que de alguma forma mencionavam a PNEEPEI nos anos de 2016, 2018 e 2019.

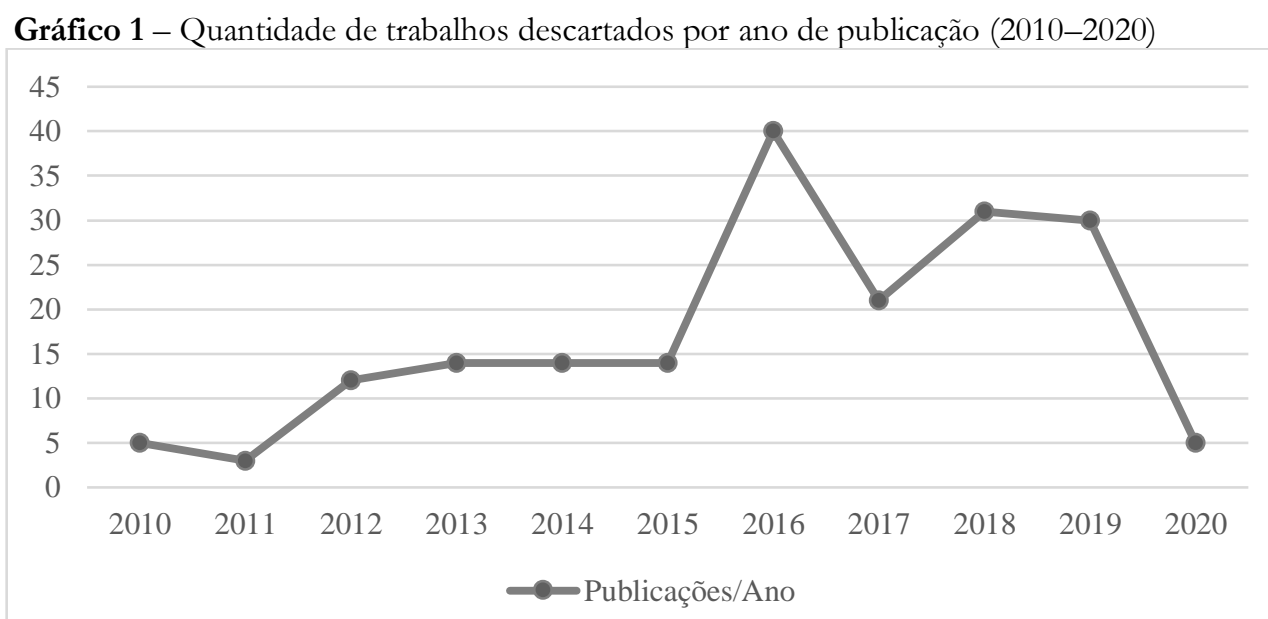

Fonte: Elaboração própria com base nos trabalhos encontrados nos portais da Capes, Google Acadêmico e SciELO.

Como critérios de descarte, foram desconsiderados os trabalhos que mencionavam a política para abordagem de deficiências/transtornos específicos; os que propuseram o estudo da implementação da PNEEPEI/2008 a partir de contextos locais, sem que fosse realizada uma análise propriamente da política mencionada; os que citavam a política, mas não discutiam especificamente sobre a modalidade da Educação Especial; os que mencionavam a PNEEPEI/2008 para análise de temas específicos como formação docente, políticas, programa e serviços voltados para o público-alvo da Educação Especial, o Atendimento Educacional Especializado, entre outros debates. Também foram desconsiderados trabalhos de conclusão de curso, teses e dissertações que foram localizados no Google Acadêmico. À medida que os trabalhos foram sendo avaliados, com base no título e resumo, foi criada uma tabela a fim de quantificar os artigos que estavam sendo descartados e quais temáticas abordavam em seu núcleo central, como pode ser identificado na Tabela 2:

Tabela 2 - Quantitativo de trabalhos descartados distribuídos por temática

\begin{tabular}{|c|c|}
\hline Categorias & Quantitativo \\
\hline Abordagem de deficiências/transtornos específicos & 42 \\
\hline Implementação da PNEE em contextos locais & 38 \\
\hline Formação docente & 22 \\
\hline $\begin{array}{c}\text { Políticas; Programas e serviços voltados para pessoas } \\
\text { com deficiência }\end{array}$ & 18 \\
\hline Não tem relação com a Educação Especial & 16 \\
\hline TCC/Dissertação/Tese & 14 \\
\hline Atendimento Educacional Especializado & 10 \\
\hline Outros & 29 \\
\hline Total & 189 \\
\hline
\end{tabular}


A partir desses dados, foi criado um quadro com os artigos que indicavam contribuir com o objetivo principal deste trabalho, ou seja, o de analisar a PNEEPEI, ainda que se enquadrassem nos critérios de descarte previamente apresentados. Durante essa etapa, pôde ser percebido que alguns trabalhos se repetiam nos portais analisados; diante disso, identificou-se que o quantitativo inicialmente apresentado de 33 trabalhos selecionados acabava por quantificar repetidamente os artigos presentes em mais de um portal. Portanto, optou-se por elaborar um quadro com os principais dados pertinentes aos trabalhos, demonstrando em quais portais tais artigos puderam ser localizados, como forma de eliminar as repetições encontradas nesse processo, como será demonstrado a seguir:

Quadro 1 - Trabalhos selecionados nos portais da Capes, Google Acadêmico e SciELO.

\begin{tabular}{|c|c|c|c|c|c|c|c|}
\hline Título & Ano & Autor(es) & $\begin{array}{l}\text { Institui- } \\
\text { ção }\end{array}$ & Publicação & 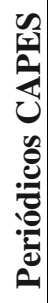 & 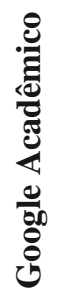 & $\frac{0}{\frac{\pi}{e n}}$ \\
\hline 1. Práticas institucionais e inclusão escolar & 2010 & NABUCO & $\begin{array}{l}\text { CAPCA/ } \\
\text { França }\end{array}$ & $\begin{array}{l}\text { Cadernos de } \\
\text { Pesquisa }\end{array}$ & $*$ & & $*$ \\
\hline $\begin{array}{l}\text { 2. Educação Especial na perspectiva da } \\
\text { educação inclusiva: desafios da } \\
\text { implantação de uma política nacional }\end{array}$ & 2011 & KASSAR & UFMS & $\begin{array}{l}\text { Educar em } \\
\text { Revista }\end{array}$ & $*$ & $*$ & $*$ \\
\hline $\begin{array}{l}\text { 3. Do Nada ao Tudo: políticas públicas e } \\
\text { a Educação Especial brasileira }\end{array}$ & 2012 & $\begin{array}{l}\text { MACHADO; } \\
\text { PAN }\end{array}$ & UFPR & $\begin{array}{l}\text { Educação \& } \\
\text { Realidade }\end{array}$ & $*$ & & $*$ \\
\hline $\begin{array}{l}\text { 4. A in/exclusão e a formação docente: } \\
\text { uma discussão a partir dos estudos } \\
\text { foucaultianos }\end{array}$ & 2012 & GARBINI & UNISC & $\begin{array}{l}\text { Revista } \\
\text { Espaço } \\
\text { Acadêmico }\end{array}$ & $*$ & & \\
\hline $\begin{array}{l}\text { 5. Educação bilíngue para surdos e } \\
\text { inclusão segundo a Política Nacional de } \\
\text { Educação Especial e o Decreto } \mathrm{n}^{\circ} \\
5.626 / 05\end{array}$ & 2013 & LODI & USP & $\begin{array}{l}\text { Educação e } \\
\text { Pesquisa }\end{array}$ & $*$ & $*$ & $*$ \\
\hline $\begin{array}{l}\text { 6. Setembro Azul: mobilização política } \\
\text { nacional a favor das escolas bilíngues } \\
\text { para surdos }\end{array}$ & 2014 & $\begin{array}{l}\text { SILVA; } \\
\text { ASSÊNCIO }\end{array}$ & USP & Ponto Urbe & $*$ & & \\
\hline $\begin{array}{l}\text { 7. Análise da estrutura organizacional e } \\
\text { conceitual da Educação Especial } \\
\text { brasileira (2008-2013) }\end{array}$ & 2014 & $\begin{array}{l}\text { HARLOS; } \\
\text { DENARI; } \\
\text { ORLANDO }\end{array}$ & $\begin{array}{l}\text { IFPR/ } \\
\text { UFSCAR }\end{array}$ & $\begin{array}{c}\text { Revista } \\
\text { Brasileira de } \\
\text { Educação } \\
\text { Especial } \\
\end{array}$ & $*$ & & * \\
\hline $\begin{array}{l}\text { 8. Novos 'referenciais' cognitivos e } \\
\text { normativos para a política nacional de } \\
\text { Educação Especial no Brasil }\end{array}$ & 2014 & $\begin{array}{l}\text { SANTOS; } \\
\text { BAPTISTA }\end{array}$ & UFRGS & $\begin{array}{c}\text { Revista } \\
\text { Práxis } \\
\text { Educacional }\end{array}$ & & * & \\
\hline $\begin{array}{l}\text { 9. Gestão democrática e luta por } \\
\text { reconhecimento na educação de surdos }\end{array}$ & 2015 & $\begin{array}{l}\text { RODRIGUES; } \\
\text { RAMPE- } \\
\text { LOTTO }\end{array}$ & UFSM & $\begin{array}{c}\text { Revista de } \\
\text { Gestão e } \\
\text { Avaliação } \\
\text { Educacional }\end{array}$ & $*$ & & \\
\hline $\begin{array}{l}\text { 10. Política Nacional da Educação Especial } \\
\text { na perspectiva da Educação Inclusiva: } \\
\text { diretrizes para alunos surdos }\end{array}$ & 2016 & $\begin{array}{l}\text { SILVEIRA; } \\
\text { COSTA }\end{array}$ & UFPA & Cap. Livro & & $*$ & \\
\hline $\begin{array}{l}\text { 11. Política nacional de Educação Especial } \\
\text { na perspectiva da educação inclusiva de } \\
\text { 2008: quais origens e quais trajetórias? }\end{array}$ & 2018 & $\begin{array}{l}\text { CORREIA; } \\
\text { BAPTISTA }\end{array}$ & UFRGS & $\begin{array}{c}\text { Revista de } \\
\text { Política e } \\
\text { Gestão } \\
\text { Educacional }\end{array}$ & $*$ & $*$ & \\
\hline
\end{tabular}

Educação em Revista|Belo Horizonte|v.37|e26361|2021 


\begin{tabular}{|c|c|c|c|c|c|c|c|}
\hline $\begin{array}{l}\text { 12. Uma década da política nacional de } \\
\text { Educação Especial na perspectiva da } \\
\text { educação inclusiva: do ideal ao possível }\end{array}$ & 2018 & $\begin{array}{l}\text { SILVA; } \\
\text { SOUZA; } \\
\text { FALEIRO }\end{array}$ & $\begin{array}{l}\text { UFU/ } \\
\text { UFG }\end{array}$ & $\begin{array}{l}\text { Revista de } \\
\text { Política e } \\
\text { Gestão } \\
\text { Educacional }\end{array}$ & $*$ & $*$ & \\
\hline $\begin{array}{l}\text { 13. Política de Educação Especial: } \\
\text { considerações sobre público-alvo, } \\
\text { formação de professores } \\
\text { financiamento }\end{array}$ & 2018 & MANZINI & UNESP & $\begin{array}{l}\text { Revista de } \\
\text { Política e } \\
\text { Gestão } \\
\text { Educacional }\end{array}$ & $*$ & $*$ & \\
\hline $\begin{array}{l}\text { 14. A lógica medicalizante nas políticas } \\
\text { públicas de educação }\end{array}$ & 2018 & $\begin{array}{l}\text { SILVA; } \\
\text { ANGE- } \\
\text { LUCCI }\end{array}$ & USP & $\begin{array}{l}\text { Revista } \\
\text { Educação } \\
\text { Especial }\end{array}$ & $*$ & & \\
\hline $\begin{array}{l}\text { 15. Política de Educação Especial e os } \\
\text { Desafios de uma Perspectiva Inclusiva }\end{array}$ & 2019 & $\begin{array}{c}\text { NEVES; } \\
\text { RAHME; } \\
\text { FERREIRA } \\
\end{array}$ & $\begin{array}{l}\text { UFMG/ } \\
\text { UFOP }\end{array}$ & $\begin{array}{l}\text { Educação \& } \\
\text { Realidade }\end{array}$ & $*$ & & * \\
\hline $\begin{array}{l}\text { 16. Política de Educação Especial: sobre } \\
\text { ambivalência, tensão e indeterminação }\end{array}$ & 2019 & ULLRICH & UFRGS & $\begin{array}{l}\text { Educação \& } \\
\text { Realidade }\end{array}$ & $*$ & & * \\
\hline $\begin{array}{l}\text { 17. Embates e disputas na política } \\
\text { nacional de Educação } \\
\text { Especial brasileira }\end{array}$ & 2019 & $\begin{array}{l}\text { KASSAR; } \\
\text { REBELO; } \\
\text { OLIVEIRA }\end{array}$ & $\begin{array}{l}\text { UFMS/ } \\
\text { UCDB }\end{array}$ & $\begin{array}{l}\text { Educação e } \\
\text { Pesquisa }\end{array}$ & & $*$ & * \\
\hline $\begin{array}{l}\text { 18. Política pública, Educação Especial e } \\
\text { escolarização no Brasil }\end{array}$ & 2019 & BAPTISTA & UFRGS & $\begin{array}{l}\text { Educação e } \\
\text { Pesquisa }\end{array}$ & & & * \\
\hline $\begin{array}{l}\text { 19. A Proposta de atualização da Política } \\
\text { Nacional de Educação Especial em } \\
\text { relação à inclusão de alunos com } \\
\text { deficiência no Ensino Superior }\end{array}$ & 2019 & $\begin{array}{l}\text { SHIMITE; } \\
\text { SILVA }\end{array}$ & UNESP & $\begin{array}{l}\text { Revista } \\
\text { Educação, } \\
\text { Psicologia e } \\
\text { Interfaces }\end{array}$ & & * & \\
\hline $\begin{array}{l}\text { 20. A participação da sociedade e o caso da } \\
\text { política nacional de Educação Especial } \\
\text { na perspectiva da educação inclusiva: } \\
\text { refletindo sobre a formação de } \\
\text { professores }\end{array}$ & 2020 & $\begin{array}{l}\text { SENNA; } \\
\text { SANTOS; } \\
\text { LEMOS }\end{array}$ & UFRJ & $\begin{array}{l}\text { Revista } \\
\text { Aleph }\end{array}$ & & $*$ & \\
\hline
\end{tabular}

Fonte: Elaboração própria com base nos trabalhos encontrados nos portais da Capes, Google Acadêmico e SciELO.

É importante destacar que os artigos selecionados representam uma amostra dos trabalhos que foram desenvolvidos com o objetivo de analisar a referida política, pois, pela necessidade de serem estabelecidos os descritores de busca, possivelmente os resultados foram limitados. Portanto, a partir da utilização desse recorte, não seria possível conhecer a totalidade de produções acerca desse tema. Assim, ao fim do processo de seleção, foram escolhidos 20 artigos científicos para serem integralmente analisados como forma de extrair o máximo de informações possíveis sobre as produções realizadas entre 2010 e 2020 que tiveram como objeto de investigação a PNEEPEI/2008.

\section{Perfil dos estudos selecionados}

A partir da análise dos dados apresentados no quadro anterior, é possível afirmar que a maioria dos trabalhos foi publicada nos anos de 2018 e 2019, totalizando nove artigos, ou seja, 45\% dos títulos que foram selecionados, como demonstrado no seguinte gráfico:

Gráfico 2 - Quantidade de trabalhos selecionados por ano de publicação (2010-2020) 


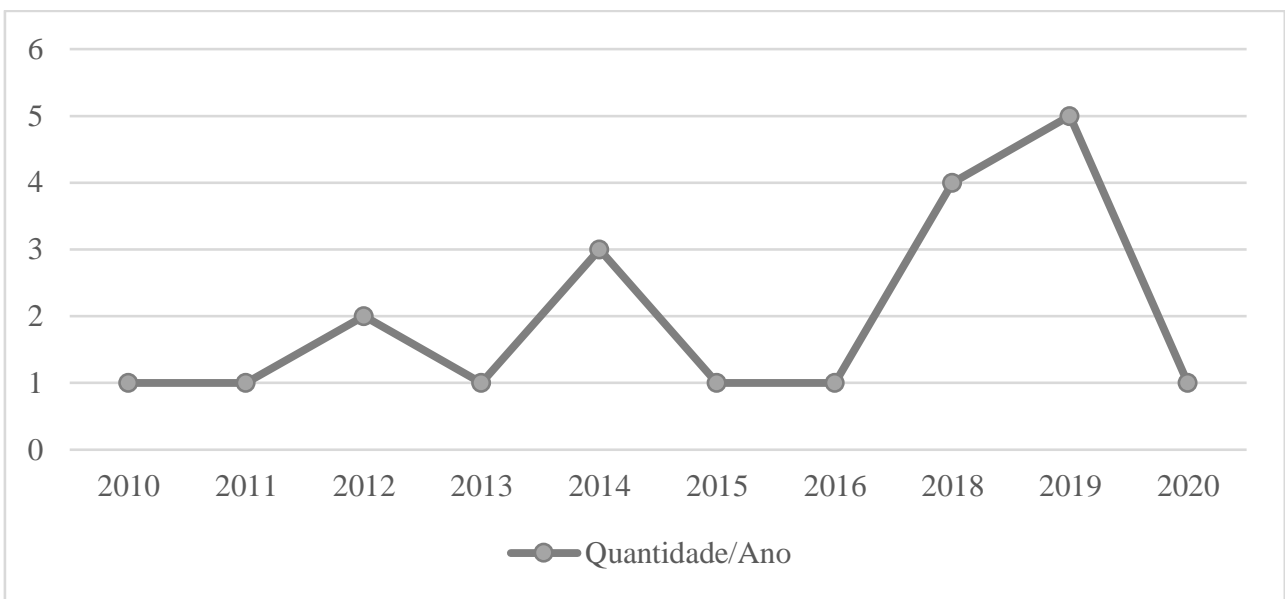

Fonte: Elaboração própria com base nos trabalhos encontrados nos portais da Capes, Google Acadêmico e SciELO.

Esse dado demonstra que a maioria dos trabalhos encontrados foi publicada após o período de dez anos de divulgação da PNEEPEI. É preciso destacar que, no ano de 2018, alguns periódicos elaboraram dossiês em comemoração ao decênio da política, e esse fato pode ter contribuído para o aumento do quantitativo de produções que privilegiaram esse assunto nesse período. Como forma de quantificar o predomínio de trabalhos produzidos, considerando as instituições às quais os autores são vinculados, foi desenvolvido o gráfico abaixo:

Gráfico 3 - Quantidade de trabalhos selecionados por instituição.

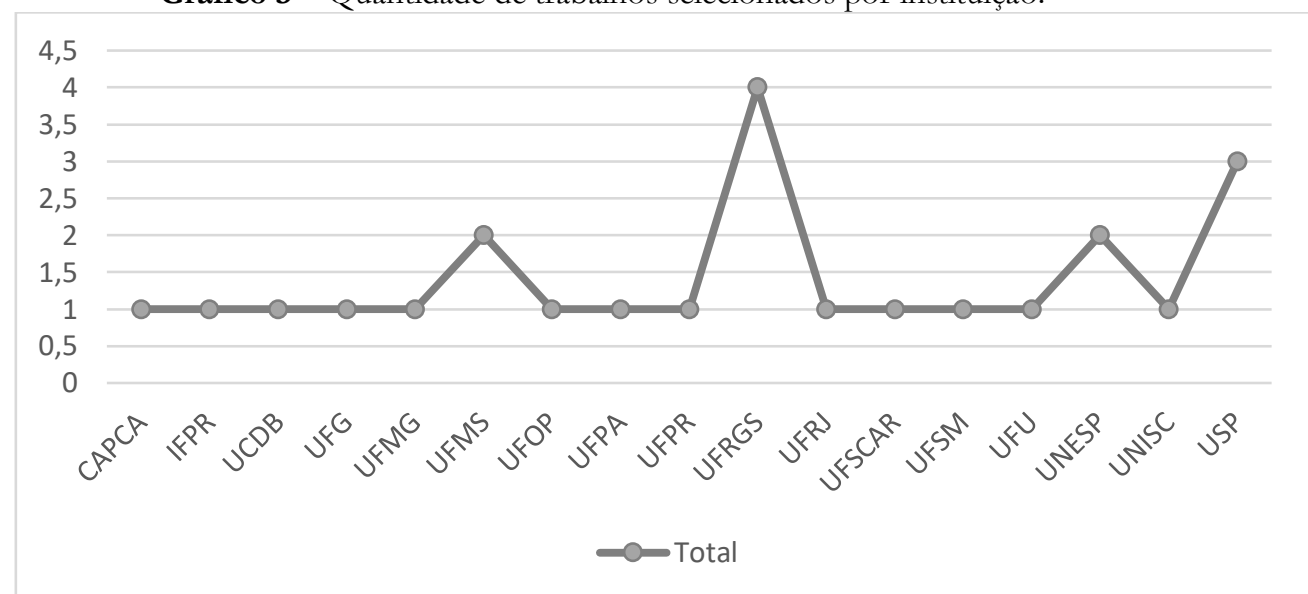

Fonte: Elaboração própria com base nos trabalhos encontrados nos portais da Capes, Google Acadêmico e SciELO.

Verifica-se uma predominância de trabalhos produzidos por autores vinculados à Universidade Federal do Rio Grande do Sul (UFRGS) e à Universidade de São Paulo (USP). Por meio da realização de um balanço de produção de teses e dissertações em Educação Especial e Educação Inclusiva desenvolvidas em programas de pós-graduação em Educação no Brasil, Silva (2018) pôde identificar que 11 programas concentram 49,3\% das produções vinculadas a essa temática no País. Alguns desses programas ${ }^{7}$, em acordo com o destaque feito anteriormente, estão vinculados à UFSCAR, UFRGS, USP, UNESP, UFSM. O autor ainda afirma que, com exceção da UNESP, os programas de Educação vinculados às instituições citadas fazem parte do que Silva (2018, p. 610) apontou como os "pioneiros" no desenvolvimento de pesquisas sobre a Educação Especial, destacando-os como "os principais centros formadores e desenvolvedores de dissertações e teses na área deve-se entre outros motivos, ao fato de esses programas possuírem no seu interior $\mathrm{AC}^{8} \mathrm{e} / \mathrm{ou} \mathrm{LP}^{9}$ voltadas à pesquisa em Educação Especial". Entretanto, o mesmo autor chamou a atenção para o fato de que, no período entre

\footnotetext{
${ }^{7}$ Silva (2018) destacou que os trabalhos vinculados ao tema da Educação Especial e Inclusiva se concentram na UFSCAR, UERJ; UFRGS; USP; UNESP/Mar; UFES; UFSM; Unicamp; UFBA; Unimep e UFRN.

8 Área de concentração.

${ }^{9}$ Linha de pesquisa.
} 
1999 e 2016, ocorre a consolidação de pesquisas no âmbito da educação especial em algumas instituições fora da região Sul-Sudeste, tais como a UFBA, UFRN, UFMA, UFAM, UCB, UEPA, UFGD, UFC e UFPB (2018, p. 610). Todavia, apesar de Silva identificar a expansão e a relevância na produção acadêmica dos programas de Educação localizados em áreas distintas aos tradicionais eixo Sul-Sudeste, o quadro 1 ainda confirma a concentração, em relação aos trabalhos que têm o objetivo de analisar a PNPPEI, dos periódicos científicos no campo da educação especial nessas regiões, tais como as revistas Cadernos de Pesquisa, Educação e Pesquisa, Revista Brasileira de Educação Especial e Revista de Política e Gestão Educacional (região Sudeste ) e Educação e Realidade (região Sul).

Destaca-se que o gráfico anterior ainda aponta a prevalência de artigos que foram produzidos por autores vinculados a instituições localizadas nas regiões Sudeste e Sul do Brasil, respectivamente. Esse fato vai ao encontro dos dados que indicam o predomínio de Instituições de Ensino Superior (IES) localizadas na região Sudeste, sendo esse fenômeno descrito por Ristoff (2008, p. 43) como "Sudestificação da educação superior", demonstrando a existência de grande desequilíbrio regional na organização das IES no País. Sobre esse fato, cabe destacar que, em análise dos dados apresentados nas Sinopses Estatísticas da Educação Superior - Graduação, divulgadas pelo Instituto Nacional de Estudos e Pesquisas Educacionais Anísio Teixeira (INEP), no ano de 2018, foram reconhecidas 2.537 IES, dentre públicas e privadas em todo território nacional, sendo que a região Sudeste, sozinha, é responsável pela concentração de 1.126 IES, ou seja, aproximadamente 44\% das instituições de todo o País (BRASIL, 2018a).

Esse mesmo fenômeno pode ser encontrado considerando-se a concentração de periódicos na região Sudeste brasileira, como apontado pelo Diretório Brasileiro de Periódicos em Educação do Fórum de Editores de Periódicos da Área de Educação (FEPAE), organizado pela Associação Nacional de Pós-Graduação e Pesquisa em Educação (ANPEd). Com o objetivo de dar visibilidade aos periódicos da área de Educação, o Diretório (2018) divulgou que em 2018 existiam 153 periódicos de acesso aberto relacionados à temática educacional no Brasil, distribuídos da seguinte forma:

Tabela 3 - Quantitativo de periódicos distribuídos por região e porcentagem

\begin{tabular}{lcc}
\hline Região & Quantitativo & Porcentagem \\
\hline Sudeste & 65 & $42,5 \%$ \\
\hline Sul & 53 & $34,6 \%$ \\
\hline Nordeste & 18 & $11,7 \%$ \\
\hline Centro-Oeste & 12 & $7,9 \%$ \\
\hline Norte & 5 & $3,3 \%$ \\
\hline Total & 153 & $100 \%$
\end{tabular}

Fonte: Elaboração própria com base nos dados divulgados pelo Diretório de Periódicos Nacionais em Educação/2018.

Outro dado analisado abordou o quantitativo de publicações vinculadas aos periódicos descritos no Quadro 1, sendo possível observar que "Educação \& Realidade", "Educação e Pesquisa" e "Revista de Política e Gestão Educacional" concentram a maior parte dos trabalhos que foram selecionados para a análise no presente estudo. Cabe destacar que, dentre os artigos selecionados, dez foram publicados em periódicos localizados na região Sudeste; sete na região Sul; um na região CentroOeste; um na região Norte; e um na região Nordeste - ratificando o conceito de "sudestificação" previamente mencionado.

Gráfico 4 - Quantidade de trabalhos selecionados por periódico 


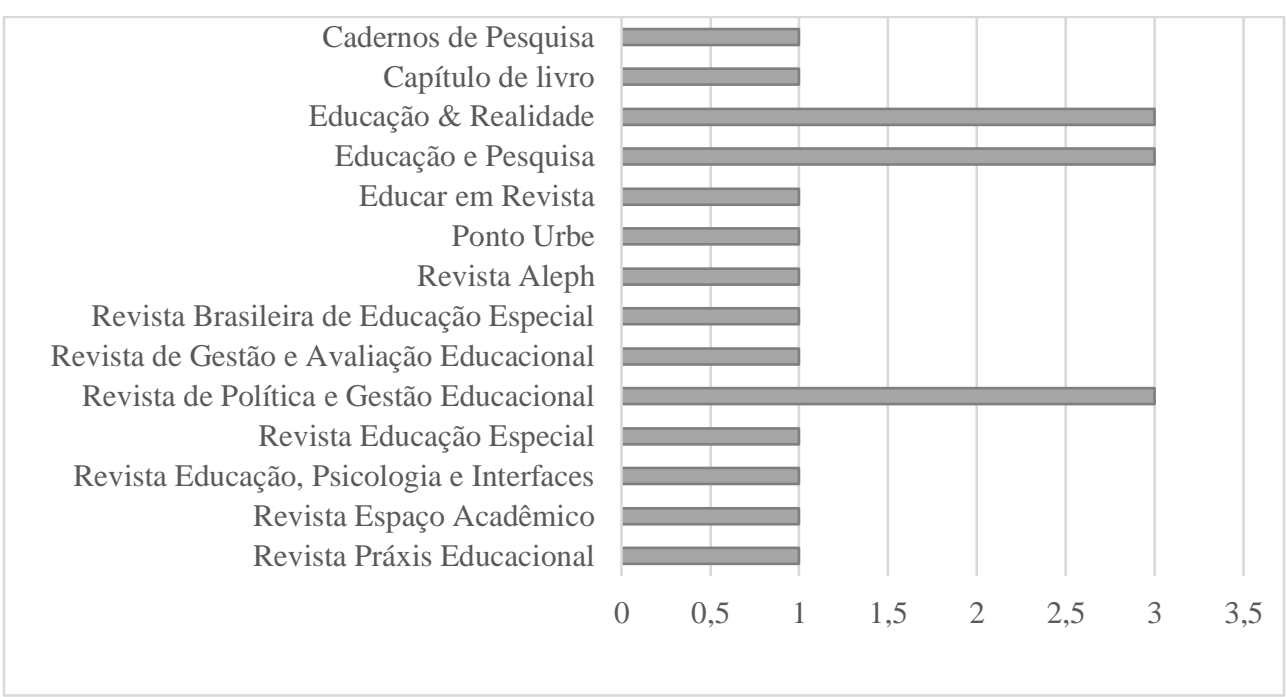

Fonte: Elaboração própria com base nos trabalhos encontrados nos portais da Capes, Google Acadêmico e SciELO.

Com base nesses apontamentos, busca-se compreender nas produções analisadas as críticas, positivas e/ou negativas, direcionadas à PNEEPEI como forma de buscar desvelar se tais apontamentos repercutiram na reformulação da referida política, considerando que no dia 30 de setembro de 2020 foi divulgado o Decreto 10.502/20, que instituiu a nova Política Nacional de Educação Especial: Equitativa, Inclusiva e com Aprendizado ao Longo da Vida (BRASIL, 2020a).

\section{A POLÍTICA NACIONAL DE EDUCAÇÃO ESPECIAL NA PERSPECTIVA DA EDUCAÇÃO INCLUSIVA (PNEEPEI) NA PRODUÇÃO CIENTÍ́FICA BRASILEIRA}

No mês de janeiro de 2008, a Secretaria de Educação Especial - SEESP - apresentou a Política Nacional de Educação Especial na Perspectiva da Educação Inclusiva - PNEEPEI -, que determinava como principal diretriz a construção dos sistemas educacionais inclusivos, na qual garantia o direito de todos à educação, determinando os objetivos de assegurar

o acesso, a participação e a aprendizagem dos alunos com deficiência, transtornos globais do desenvolvimento e altas habilidades/superdotação nas escolas regulares, orientando os sistemas de ensino para promover respostas às necessidades educacionais especiais (Brasil, 2008, s.p.).

Esse trecho evidencia que a matrícula do referido público-alvo deveria ser realizada nas escolas regulares, pois, "a partir dos referenciais para a construção de sistemas educacionais inclusivos, a organização de escolas e classes especiais passa a ser repensada, implicando uma mudança estrutural e cultural da escola para que todos os alunos tenham suas especificidades atendidas" (Brasil, 2008, s.p.). Garcia (2017, p. 47) chamou a atenção para o fato de que a função substitutiva da educação especial com relação ao ensino regular foi abolida na referida política, uma vez que a "ideia em si, trabalhada discursivamente como segregação, foi banida do escopo politicamente correto da proposta", articulando, assim, a matrícula compulsória na escola regular à bandeira ideológica da inclusão.

Já a proposta de atualização da PNEEPEI foi apresentada no dia 16 de abril de 2018, em uma reunião da qual participaram representantes do MEC, do Conselho Nacional de Educação (CNE) e de instituições privadas de caráter assistencial que historicamente ofertam serviços aos sujeitos públicoalvo da Educação Especial (PAEE). Tal projeto passou a ser debatido por alguns setores da sociedade, como associações científicas, profissionais da área, estudantes e movimentos sociais diversos (SILVA; MACHADO; SILVA, 2019). Ainda no ano de 2018, foi disponibilizado um documento para consulta pública com a proposta de atualização da PNEEPEI, que sugeria que as mudanças processadas na educação nos últimos anos exigiam ações que respondessem à nova realidade social, respaldadas no diálogo com a sociedade.

Apesar disso, de acordo com Silva, Machado e Silva (2019), diversas instituições manifestaram seu descontentamento com os meios autoritários e antidemocráticos com os quais o MEC apresentava e encaminhava a proposta de atualização da política. Considerando que as críticas conferidas 
pelas produções acadêmicas têm sido utilizadas como instrumentos no processo de reformulação da PNEEPEI, destaca-se a necessidade de compreender, de acordo com a amostra de trabalhos selecionada, os posicionamentos dos autores que discorreram no período de 2010-2020 sobre a política acima mencionada.

Inicialmente, os textos selecionados foram lidos integralmente a fim de que fossem estabelecidas categorias de análise com base nas discussões apresentadas. Cabe destacar que, apesar de todos os textos terem sido lidos de forma integral, como estratégia metodológica assumida na condução do balanço de produção, optou-se por utilizar somente os trechos dos trabalhos que se referiam especificamente à PNEEPEI, sendo desconsiderados os debates que citavam a Educação Especial, mas não possuíam relação com a política mencionada. Os textos analisados foram agrupados em cinco categorias desenvolvidas a seguir.

\section{Categorização do público-alvo da Educação Especial}

Após a análise de todos os trabalhos, foram selecionados três que convergiam em relação à discussão específica sobre a categorização do público-alvo da Educação Especial (PAEE), expresso na PNEEPEI. Nesta categoria, Nabuco (2010) e Silva e Angelucci (2018) destacaram que a política reforça o caráter médico-psicológico presente historicamente nas políticas de Educação Especial no Brasil, ressaltando a perpetuação do deslocamento de questões de ordem política e institucional para aspectos individuais. Porém, na contramão dos trabalhos anteriormente citados, Ullrich (2019) destaca que, por meio da crítica à retórica médico-psicológica, a PNEEPEI buscou adotar uma perspectiva social com a adesão ao discurso inclusivo.

Com os fundamentos teóricos da psicanálise, Nabuco (2010) afirma que, ao analisar a política, foi possível identificar o que denominou por "psicopatologia da inclusão", destacando que o Brasil é um dos raros países que continua utilizando a expressão "Educação Especial". Em função disso, considera não ser possível conceber a educação como inclusiva a partir de uma política que mantém uma expressão que produz a fabricação da categoria de desviantes estigmatizados. Também com o objetivo de problematizar a manutenção da expressão "Educação Especial", Ullrich (2019) questiona se seria possível sustentar uma posição teórica que defenda a proposta de inserir a Educação Especial e a educação inclusiva em situação de coexistência, considerando que, em muitos momentos, tais concepções foram consideradas opostas no debate educacional. Ainda sobre esse aspecto, e em consonância com o autor anteriormente citado, Nabuco (2010, p. 67) afirma que tais orientações são construídas "a partir de paradigmas opostos, de categorias conceituais distintas cujos efeitos objetivos definem uma pluralidade de instituições e práticas".

Nabuco (2010) ainda enfatiza que as categorizações do PAEE mencionadas na política são reducionistas e acentuam as fronteiras entre o normal e o patológico, contribuindo para que a PNEEPEI assuma o seu lugar simbólico de regulação das diferenças insuperáveis dos sujeitos ao propor uma classificação de comportamentos observáveis. Na mesma direção, Silva e Angelucci (2018) indicaram que foi possível observar a permanência da lógica medicalizante ${ }^{10}$ na PNEEPEI, principalmente pela existência de terminologias "emprestadas do campo da saúde" e, portanto, consideradas inadequadas para definir aspectos relativos ao processo de escolarização. Assim, as autoras apontam a necessidade de a educação "produzir formas de compreender as/os estudantes e seus processos de ensino-aprendizagem fora do eixo patologia/normalidade, afirmando radicalmente a diversidade humana como princípio, meio e fim do trabalho educativo" (SILVA; ANGELUCCI, 2018, p. 683).

Embora Silva e Angelucci (2018) e Ullrich (2019) concordem que a PNEEPEI representa um importante avanço para a garantia do acesso de alunos com diferenças funcionais à escola regular e aos serviços especializados, identifica-se que, enquanto Ullrich (2019) defende que a PNEEPEI espera superar a lógica do modelo clínico-terapêutico, fazendo com que a escola se torne protagonista na superação da exclusão, as autoras destacam que a política é produto da correlação de forças marcada pela

\footnotetext{
${ }^{10}$ Collares e Moysés (2010) apresentaram a medicalização como uma transformação artificial de questões que não eram do âmbito da medicina em problemas médicos. As mesmas autoras argumentaram que, nesse contexto, as questões coletivas são tomadas como individuais, e os problemas sociais e políticos, como biológicos. 
lógica medicalizante, revelada de forma expressa na definição do PAEE a partir de categorias diagnósticas oriundas do campo da saúde, em uma perspectiva biomédica (SILVA; ANGELUCCI, 2018).

Ullrich (2019) conclui que a PNEEPEI pode ser compreendida como uma crítica, mesmo que enviesada, ao próprio projeto no qual tal modalidade educacional tem suas raízes, desconsiderando a tensão existente entre o conceito de inclusão e sua relação com a ideia de exclusão, expressando-se, assim, em clara ambiguidade. Da mesma forma, Nabuco (2010) também indica que, historicamente, a modalidade da Educação Especial repousa sobre contradições sociais de categorias, citando como exemplo as noções sobre deficiência e inadaptação, bem como as instituições e seus públicos específicos. Nesse sentido, a autora ainda afirma que os debates em torno da Educação Especial e da Educação Inclusiva fazem parte de uma psicopatologia contemporânea ao implicarem julgamentos de valor e gestão de comportamentos (NABUCO, 2010).

\section{A PNEEPEI e educação de surdos}

Para esta categoria, foram delimitados quatro trabalhos: Lodi (2013); Silva e Assênsio (2014); Rodrigues e Rampelotto (2015); e Silveira e Costa (2016). Todos os trabalhos versam sobre a proposta de educação de surdos e de ensino bilíngue expressa na PNEEPEI. Porém, enquanto Lodi (2013) e Silveira e Costa (2016) discutiram essa temática a partir da realização de análise documental propriamente, Silva e Assênsio (2014) e Rodrigues e Rampelotto (2015) buscaram problematizar tal proposta a partir dos movimentos que foram iniciados com a divulgação da política. É preciso destacar que, ao propor a obrigatoriedade da matrícula dos alunos PAEE na escola regular, a PNEEPEI indicou que o ensino nas instituições especializadas deveria ser repensado, sob o argumento da necessidade da constituição de um sistema educacional inclusivo no Brasil.

Assim, com o objetivo de analisar as diretrizes apontadas na PNEEPEI para inclusão de alunos surdos no ensino regular e desvendar os diferentes sentidos de educação bilíngue e de inclusão expressos no documento, Lodi (2013) e Silveira e Costa (2016) apontaram que a educação de surdos se constitui como um campo específico do conhecimento, distanciando-se da Educação Especial (LODI, 2013). Portanto, seria necessária a criação de um conjunto de estratégias que "possibilite o reconhecimento de sua especificidade tanto linguística quanto cultural, ou seja, o reconhecimento da cultura surda e da Língua de Sinais própria desta comunidade" (SILVEIRA; COSTA, 2016, p. 132).

Especificamente sobre a proposta de educação de surdos na política analisada, Lodi (2013) indica que a PNEEPEI reduziu a educação bilíngue à presença de duas línguas no interior da escola, impossibilitando que cada uma pudesse assumir seu lugar de pertinência para os grupos que as utilizam, mantendo, assim, a hegemonia do Português nos processos educacionais. Sobre essa discussão, Silveira e Costa (2016, p. 133) defendem que o ensino dos surdos deve prioritariamente acontecer em Libras como sua primeira língua, uma vez que essa proposta "se caracteriza como elemento fundamental para aprimoramento de conhecimentos e reconhecimento da Língua Brasileira de Sinais nos aspectos linguísticos e cultural, bem como fomenta a construção da identidade surda".

Silveira e Costa (2016) reconhecem alguns avanços na PNEEPEI com relação à educação de surdos, citando, como exemplo, o apontamento da Educação Bilíngue; o indicativo da ação do intérprete de Libras; e a formação do professor do AEE em uma perspectiva bilíngue. No entanto, os autores também identificaram pontos de fragilidades com relação à baixa problematização teóricometodológica sobre a proposta de bilinguismo presente no documento analisado. Já Lodi (2013) indica que a forma como a PNEEPEI foi estruturada "limita a transformação proposta para a educação de surdos apenas no plano discursivo e restringe a inclusão à escola, impossibilitando uma ampliação desse conceito a todas as esferas sociais" (LODI, 2013, p. 49), impedindo o estabelecimento de diálogos com as comunidades surdas brasileiras.

A partir de uma pesquisa etnográfica, Silva e Assênsio (2014) descreveram a mobilização política nacional em favor das escolas bilíngues para surdos, apontando que tal movimento surgiu tecendo críticas à PNEEPEI, compreendida como o pontapé inicial para o fechamento das escolas especiais, o que gerou tensões entre os defensores da educação inclusiva e da manutenção das escolas especiais para surdos. Também com a finalidade de compreender a luta pelo reconhecimento da educação de surdos, Rodrigues e Rampelotto (2015) analisaram os movimentos de pessoas surdas para a 
manutenção do funcionamento das escolas para esse público específico e os conflitos inerentes ao processo de educação inclusiva, referenciada na PNEEPEI.

Silva e Assênsio (2014) centraram sua análise no chamado Movimento Surdo em Favor da Educação e da Cultura Surda, que organizou, em setembro de 2011, uma série de ações em defesa das escolas bilíngues, estando presente em 24 capitais nacionais e em Brasília. O movimento Setembro Azul, como ficou conhecido, foi apontado pelos autores como uma oportunidade de conectar a Federação Nacional de Educação e Integração dos Surdos - FENEIS - aos pais de crianças/jovens surdos, profissionais de escolas especiais para surdos, pesquisadores da área e intérpretes de língua de sinais em um nível nacional. Já Rodrigues e Rampelotto (2015) construíram seu trabalho a partir da análise da experiência vivenciada pela primeira escola bilíngue fundada no município de Santa Maria/RS. Os autores destacaram que a educação de surdos, anteriormente à PNEEPEI, era representada pelas classes especiais; porém, após a divulgação da proposta inclusiva, a escola analisada passou por um constante processo de desmobilização, principalmente em função das diretrizes apontadas na referida política, já que a Educação Especial passou, obrigatoriamente, a estar vinculada ao ensino regular.

Identifica-se que Silva e Assênsio (2014) não se posicionaram em relação às diretrizes propostas na PNEEPEI sobre a educação de surdos, concentrando-se em descrever somente fatos ocorridos durante a realização de ações vinculadas ao movimento Setembro Azul. Conforme apontado pelos autores, tal movimento foi um acontecimento-chave para compreender como a mobilização política relacionada à surdez estabeleceu relações com o Estado. Destaca-se que, nos eventos acompanhados, foi constatada a unanimidade dos discursos contra o fechamento das escolas especiais, conforme indicado na PNEEPEI, o que refletiu, inclusive, na manutenção de escolas municipais de Educação Especial no município de São Paulo, que foram então transformadas em escolas municipais de educação bilíngue para surdos (SILVA; ASSÊNSIO, 2014).

Apesar de não buscarem analisar um movimento nacional como os autores anteriormente citados, com base em suas análises, e a partir de uma experiência local, Rodrigues e Rampelotto (2015) destacam que a luta por reconhecimento dos surdos perpassa pela busca de reconhecimento de suas identidades e culturas. De acordo com as experiências descritas na escola analisada, as autoras evidenciaram que existem, além de uma diferença linguística, distinções culturais entre as escolas bilíngues e as escolas comuns, indicando, portanto, que a luta dos surdos após a PNEEPEI se centrou na busca de garantir o direito de oferecer as condições de comunicação necessárias para essa comunidade (RODRIGUES; RAMPELOT'TO, 2015).

\section{O discurso inclusivo na PNEEPEI}

Para esta categoria, foram selecionados quatro trabalhos dos seguintes autores: Kassar (2011); Machado e Pan (2012); Garbini (2012); Neves, Rahme e Ferreira (2019). Os artigos escolhidos foram categorizados com base na discussão em torno do discurso inclusivo expresso na PNEEPEI e na centralidade do Atendimento Educacional Especializado (AEE) nesta proposta.

A proposta de AEE expressa na política acima citada, que deveria ser ofertada prioritariamente nas Salas de Recursos Multifuncionais (SRM), é apontada por todos os autores dessa categoria como justificativa para a construção de um "sistema educacional inclusivo", considerando que, a partir da PNEEPEI, os alunos PAEE deveriam estar matriculados no ensino regular, acompanhados, quando necessário, de AEE. A constituição de um sistema educacional inclusivo ancora-se no discurso de igualdade de direitos e oportunidades a todos (MACHADO; PAN, 2012), a partir da proposição de práticas orientadas pela igualdade e diferença como valores indissociáveis e capazes de promover a superação da lógica da exclusão (NEVES; RAHME; FERREIRA, 2019). Tal discurso, conforme apontado por Garbini (2012), ganha destaque sobretudo a partir da década de 1990, juntamente com uma série de ações de convencimento e de investimentos que legitimam a inclusão, por meio da constituição das ideias de respeito, tolerância e diversidade, sem considerar uma discussão mais ampla sobre as diferenças.

Os autores apontam que, ao argumentar sobre a necessidade de combater processos discriminatórios, contrapondo-se às práticas educacionais separadas, a PNEEPEI desconsidera a constituição histórica e social das instituições que atuaram justamente "no vácuo deixado pelo Estado brasileiro" (MACHADO; PAN, 2012, p. 287). Desconsidera, inclusive, que tais instituições, tidas 
anteriormente à política como atores principais da Educação Especial, teriam as condições de locais para ofertar AEE em caráter complementar ou suplementar ao ensino regular (KASSAR, 2011).

Portanto, ao assumir o modelo de "inclusão total" por meio da "inserção de todos, independentemente de diferenças, na classe comum da escola próxima à sua residência e a eliminação total do modelo de prestação de serviços" (MENDES ${ }^{11}, 2006$ apud MACHADO; PAN, 2012, p. 278), o Estado brasileiro deveria também assumir a responsabilidade pela modalidade historicamente sob incumbência quase que exclusiva de instituições privadas e filantrópicas. Consequentemente, o Estado também deveria arcar com as despesas exigidas pelos serviços de Educação Especial no País, optando, contudo, por uma opção de baixo custo, por meio da preferência na rede regular de ensino (MACHADO; PAN, 2012).

Tal posicionamento é reforçado por outros autores dos trabalhos incluídos nessa categorização, ao afirmarem que o estabelecimento de um único caminho para os alunos PAEE ${ }^{12}$ indica que preocupações econômicas foram determinantes na adoção de uma política orientada para o corte de gastos, como aparentemente aconteceu com a PNEEPEI (KASSAR, 2011). Nesse sentido, o discurso inclusivo efetiva-se com o "objetivo de favorecer uma lógica neoliberal, colocando todos os sujeitos na ciranda do mercado" (GARBINI, 2012, p. 26), ao caracterizar o processo de inclusão de alunos PAEE como uma questão legitimada e de caráter indiscutível. Garbini (2012, p. 30) ainda aponta que essa foi uma ação inerente à racionalidade neoliberal que "coloca todos os sujeitos nos jogos de consumo e participação, devidamente mapeados e esquadrinhados por uma malha de poder que governa e controla a todos e a cada um”.

Ainda com relação à proposta de "inclusão total", os autores destacaram que tal diretriz "calou" a voz dos beneficiários da Educação Especial no País com relação à melhor prática educacional que atenderia aos seus objetivos (MACHADO; PAN, 2012), sob risco de ocasionar, principalmente, a desconstrução de sua identidade. Especificamente sobre esse ponto, Machado e Pan (2012) e Neves, Rahme e Ferreira (2019) concordam que, ao mesmo tempo que a PNEEPEI busca a ressignificação dos sentidos atribuídos à deficiência, ao propor uma reflexão ética na busca pela melhoria das condições dessa parcela da população, tem tratado a questão da identidade com seu apagamento e não com sua afirmação. De acordo com esses autores, "se a igualdade de oportunidade deve ser assegurada pelo direito à diferença, essa diferença deve ser reconhecida, e não apagada" (MACHADO; PAN, 2012, p. 289); portanto, as diretrizes propostas na política correm o risco de "apagar a identidade e produzir a indiferença, capaz de configurar como uma nova forma de segregação" (NEVES; RAHME; FERREIRA, 2019, p. 11).

\section{O Processo de construção e desdobramentos da PNEEPEI}

Para o desenvolvimento desta categoria, foram elencados cinco trabalhos desenvolvidos por: Harlos, Denari e Orlando (2014); Santos e Baptista (2014); Correia e Baptista (2018); Baptista (2019); e Silva, Souza e Faleiro (2018). O processo de construção da PNEEPEI foi descrito por Correia e Baptista (2018) e Silva, Souza e Faleiro (2018), destacando que o marco temporal inicial foi o ano de 2006, mais especificamente quando o Brasil se tornou signatário da Convenção sobre os Direitos das Pessoas com Deficiência, aprovada pela Organização das Nações Unidas (ONU). Essa questão foi especialmente detalhada por Correia e Baptista (2018) quando ressaltaram que, ao aderir aos preceitos da Convenção, o Brasil assumiu uma série de compromissos vinculados ao âmbito educacional. As diretrizes contidas nesse documento internacional passaram a influenciar as concepções de educação e das políticas públicas direcionadas às pessoas com deficiência no Brasil por meio do

enfoque "inclusivo", baseado na crença expressa por seus defensores de que a igualdade de oportunidades somente pode ser atingida quando as pessoas com deficiência são incorporadas, em condições de igualdade, em todas as esferas econômicas, sociais e culturais de suas respectivas sociedades (CORREIA; BAPTISTA, 2018, p. 720).

\footnotetext{
${ }^{11}$ MENDES, Enicéia G. A Radicalização do Debate sobre Inclusão Escolar no Brasil. Revista Brasileira de Educação, Rio de Janeiro, v. 11, n. 33. 387-405, dez. 2006.

12 Matrícula em classe comum e o apoio de atendimento educacional especializado para complementar ou suplementar a escolaridade.
} 
O processo de elaboração da PNEEPEI ocorreu imediatamente após a Convenção, sendo citado pelos autores que, no ano de 2007, foi organizado um grupo de trabalho designado pelo MEC para desenvolver um documento síntese que fosse um produto de debates entre gestores e pesquisadores da Educação Especial, com a finalidade de anunciar as diretrizes que seriam direcionadas à modalidade (CORREIA; BAPTISTA, 2018). Como fruto dessas discussões, três principais vertentes surgiram: alguns representantes indicavam que a política favoreceria a construção de um modelo de Educação Especial diferenciado, ao propor a inclusão educacional como direito de todos; outros consideraram a legitimação do fim das escolas especiais que passaram a ser consideradas "vilãs" em relação ao processo inclusivo; e, ainda, havia os que avaliavam tal processo como um certo descompromisso do governo com tal público, uma vez que os discentes seriam transferidos para a escola regular sem que elas tivessem condições e o suporte necessário para tal realidade (SILVA; SOUZA; FALEIRO, 2018).

Silva, Souza e Faleiro (2018, p. 736) ainda afirmaram que participaram desse processo "não pessoas que agregavam conhecimentos da área, mas aqueles que iriam defender os interesses de grupos que ocupavam o poder político" (SILVA; SOUZA; FALEIRO, 2018, p. 736). Os resultados dos debates que aconteceram nesse contexto, inclusive por meio de assembleias, foram conduzidos ao Conselho Nacional de Educação (CNE), que produziu um texto e o encaminhou para o MEC em janeiro de 2008. O resultado disso foi a publicação da PNEEPEI como um texto orientador, sem a assinatura ministerial e sem a publicação de um decreto, o que determinou que a política não tivesse um caráter regulador/normatizador (SILVA; SOUZA; FALEIRO, 2018).

Em relação aos desdobramentos da PNEEPEI, Harlos, Denari e Orlando (2014), Santos e Baptista (2014) e Baptista (2019) inicialmente destacaram o desenvolvimento histórico da modalidade no País até a institucionalização da "inclusão" como perspectiva adotada na PNEEPEI. Santos e Baptista (2014) afirmam que a perspectiva inclusiva delimitada na PNEEPEI vem conferindo outros desenhos à modalidade da Educação Especial, considerando, principalmente, que, de modo claro e inequívoco, o espaço de escolarização para crianças com deficiência seria no ensino comum, reafirmando, assim, sua dimensão complementar e suplementar.

Com a divulgação da política, Baptista (2019) aponta que é possível identificar efeitos perceptíveis nos índices de matrículas dos alunos PAEE, que passaram a frequentar em maior número, de forma progressiva, as classes do ensino comum, enquanto as matrículas nas classes ou escolas especiais foram consideravelmente reduzidas. De acordo com o autor, o principal avanço da PNEEPEI foi a retirada das condições de exceção ao processo de inclusão, que permitiram, em normativas anteriores, que o AEE pudesse complementar ou substituir o ensino comum (BAPTISTA, 2019). Harlos, Denari e Orlando (2014) também concordam que a estrutura organizacional e conceitual da Educação Especial a partir da PNEEPEI apresenta avanços em relação às estruturas que a precederam, principalmente sobre a perspectiva da inclusão total e a oposição à educação especializada e substitutiva ao ensino regular. Os mesmos autores, contudo, também destacaram algumas críticas.

Os autores ressaltaram como pontos negativos: a delimitação de um determinado públicoalvo pela PNEEPEI, negligenciando outros segmentos que poderiam demandar o AEE; a restrição de exigências formativas relacionadas aos professores e à ampliação de suas funções; a delimitação das SRMs como um espaço diferenciado dos destinados aos alunos ditos "normais", preservando a antinomia entre Educação Especial e educação regular; a contraposição ao modelo clínico, ao mesmo tempo que propõe propostas típicas desse modelo, como a disponibilização de espaço diferenciado e de profissionais especializados (HARLOS; DENARI; ORLANDO, 2014). Santos e Baptista (2014) também concordam que, apesar de ser possível identificar avanços no sentido da garantia do direito ao acesso e da permanência na escola comum e pública de alunos público-alvo da modalidade, esses avanços ainda são parciais, considerando as disparidades das ações e as desigualdades regionais presentes no País (SANTOS; BAPTISTA, 2014).

\section{A Proposta de atualização da PNEEPEI}

A última categoria inclui trabalhos que foram especificamente publicados nos dois últimos anos e que mencionam o processo de atualização da PNEEPEI, divulgado no ano de 2018 pela então Secretaria de Educação Continuada, Alfabetização, Diversidade e Inclusão - SECADI -, vinculada ao 
MEC. Os trabalhos selecionados que abordam esse tema foram desenvolvidos por Manzini (2018), Shimite e Silva (2019), Kassar, Rebelo e Oliveira (2019) e Senna, Santos e Lemos (2020).

Todos esses trabalhos destacam, como um dos principais pontos abordados na proposta, a menção ao retorno do caráter substitutivo da Educação Especial, ao indicar a possibilidade de essa modalidade ser ofertada em outros espaços que não a escola regular, como anteriormente indicada na PNEEPEI. A adoção da PNEEPEI e seu modelo de atendimento que privilegiou o lócus escola comum/regular pública e fomentou a matrícula dos alunos PAEE nesse espaço contribuiu para a expansão de investimentos para a implantação do AEE na escola pública. Isto indicou, portanto, a ampliação do atendimento público em detrimento do privado, fortalecendo a "canalização de recursos públicos para a escola pública" (KASSAR; REBELO; OLIVEIRA, 2019, p. 14). Porém, conforme foi destacado por Senna, Santos e Lemos, a existência da PNEEPEI é permeada por embates, pois existem os que

lutam pela educação em classes e escolas especiais, defendendo que para determinadas deficiências esta é a única solução, enquanto há aqueles que lutam por um processo de inclusão de todos nas salas de aula regulares, apesar das dificuldades existentes na organização dessa modalidade em todo o país (SENNA; SANTOS; LEMOS, 2020, p. 312).

Nesse contexto, entram em cena diferentes atores, de modo que "ora a pressão das organizações especializadas é mais audível, ora o movimento em favor da participação plena das pessoas com deficiência nas instituições não especializadas é fortalecido" (KASSAR; REBELO; OLIVEIRA, 2019, p. 5). Nesse cenário, no ano de 2018 foi apresentada a proposta de atualização da PNEEPEI com $\mathrm{o}$ argumento da "necessidade de efetivar a inclusão por meio da acessibilidade plena, tanto aos recursos para aprendizagem, quanto para eliminação de barreiras físicas" (BRASIL, 2018b ${ }^{13}$ apud SHIMITE; SILVA, 2019, p. 9), considerando a necessidade de ofertar diferentes espaços, dentro e/ou fora da escola regular, para diferentes serviços vinculados à Educação Especial.

A partir desse cenário, é possível identificar duas categorias que se articulam de diferentes formas nesses embates da Educação Especial: a alocação dos recursos públicos e o lugar de atendimento dos alunos PAEE. Shimite e Silva (2019) afirmam que o documento que apresentava a proposta de atualização surgiu acompanhado pelas críticas ao processo inclusivo proposto pela PNEEPEI. Isso significa dizer que, conforme apontado por Kassar, Rebelo e Oliveira (2019), a crítica elaborada por pesquisadores de que a modalidade vinha se restringindo ao AEE exclusivamente nas SRM passou a ser utilizada como argumento para alterações no documento da PNEEPEI, gerando mobilizações de diferentes grupos no País.

Acerca do documento que propunha a atualização, Shimite e Silva (2019) destacam que é possível verificar uma busca de incentivo financeiro do Estado às instituições privadas, ao direcionar à filantropia e às consultorias em educação inclusiva a responsabilidade para a constituição da "Educação Especial equitativa, inclusiva e ao longo da vida" (BRASIL, 2018b apud SHIMITE; SILVA, 2019, p. 17), indo na contramão do que era proposto pela política anterior. Em sintonia com essa afirmação, Manzini (2018) sugere que o suporte financeiro destinado às instituições, via terceirização dos serviços do AEE pelo Estado, evidencia que a escola pública pode se tornar ainda mais fragilizada.

Assim, tal proposta de "atualização" foi apontada por Senna, Santos e Lemos (2020) como um retrocesso, principalmente a partir de três principais pontos: pela possibilidade de retornar à Educação Especial um papel substitutivo à escola comum, como um sistema paralelo; pelo envolvimento da família e do estudante no processo decisório, possibilitando diferentes interpretações, podendo legitimar a privação desse público da participação e da aprendizagem no ensino regular; e, por fim, pela retirada do termo "na perspectiva da educação inclusiva" do nome da política. Soma-se a essa discussão o fato de essa proposta de atualização não ter sido permeada por amplos debates e discussões na sociedade em geral, sendo então caracterizada como um processo "não democrático de tomada de decisão acerca do tema, não tornando, portanto, um processo que possa ser legitimado pela sociedade" (SENNA; SANTOS; LEMOS, 2020, p. 319).

\footnotetext{
13 Minuta da Política Nacional De Educação Especial: equitativa, inclusiva e ao longo da vida. MEC/SECADI. Brasília, 2018.
} Educação em Revista|Belo Horizonte|v.37|e26361|2021 
Nesse sentido, os trabalhos analisados nessa categoria concluem que seria um grande retrocesso devolver às instituições especializadas e filantrópicas o atendimento do PAEE fora da escola pública (MANZINI, 2018), uma vez que tal proposta não visa à promoção do desenvolvimento de seu público-alvo ou de grupos específicos, por privilegiar grupos políticos e filantrópicos em detrimento dos investimentos na educação pública (SHIMITE; SILVA, 2019). Assim, ainda de acordo com os trabalhos analisados, tais propostas se apresentam como um retrocesso para o campo da inclusão em educação, considerando, principalmente, a ausência de diálogo e de participação da sociedade em sua elaboração, caracterizando-se, desse modo, mais como uma reforma imposta do que uma atualização proposta (SENNA; SANTOS; LEMOS, 2020).

Já Kassar, Rebelo e Oliveira (2019) concluem que a divulgação da proposta de atualização da PNEEPEI acirrou ainda mais os embates sobre o lócus de atendimento desses sujeitos, pois tem sido centrada, superficialmente, nas questões: "contra ou a favor da inclusão; contra ou a favor de escolas especiais; educação inclusiva ou Educação Especial” (KASSAR; REBELO; OLIVEIRA, 2019, p. 14), sendo evidenciado pelas autoras que tais disputas levaram à constituição de uma polaridade que não tem contribuído para o amadurecimento de propostas e de projetos que visam contemplar as especificidades desses alunos.

\section{CONSIDERAÇÕES FINAIS}

No dia 30 de setembro de 2020, foi publicado o Decreto 10.502/20, que instituiu a nova Política Nacional de Educação Especial: Equitativa, Inclusiva e com Aprendizado ao Longo da Vida (BRASIL, 2020a), estabelecendo uma série de alterações na Política Nacional de Educação Especial na Perspectiva da Educação Inclusiva (BRASIL, 2008). Como forma de identificar as críticas despendidas por autores brasileiros com relação à PNEEPEI e de compreender os principais pontos que foram considerados no processo de atualização dessa política, foram selecionados e analisados integralmente 20 trabalhos publicados entre os anos de 2010 e 2020. Após a análise dos textos, foram construídas cinco categorias: Categorização do público-alvo da Educação Especial; PNEEPEI e educação de surdos; Discurso inclusivo na PNEEPEI; Processo de construção e desdobramentos da PNEEPEI; e, por fim, Proposta de atualização da PNEEPEI. Como forma de compreender a possível influência das críticas conferidas pelos autores elencados à PNEEPEI em seu processo de atualização, serão retomados alguns apontamentos destacados no presente trabalho a fim de tecer comparações com o novo instrumento normativo.

Com relação à primeira categoria, apesar de considerar o avanço que a política de 2008 proporcionou ao garantir o acesso de alunos com diferenças funcionais à escola regular e ao atendimento especializado, identificam-se, como principais críticas, o reforço da PNEEPEI ao caráter médicopedagógico na categorização dos alunos público-alvo da Educação Especial (PAEE) e a manutenção dessa nomenclatura, considerada pelos autores como oposta à perspectiva inclusiva. A partir da análise do Decreto, pôde ser percebido que a categorização do PAEE permaneceu inalterada, considerando a política predecessora, bem como a expressão "Educação Especial" atrelada ao nome da política. Porém, em oposição à política de 2008, o novo decreto estabeleceu novos adjetivos à Política Nacional de Educação Especial (PNEE), pelo acréscimo dos termos "Equitativa, Inclusiva e com Aprendizado ao Longo da Vida", permanecendo, de acordo com os textos analisados, a dualidade entre a modalidade da Educação Especial e a proposta inclusiva (BRASIL, 2020a).

$\mathrm{Na}$ segunda categoria, alguns atores ressaltaram que a educação de surdos se constitui como um campo específico do conhecimento e, nesse sentido, distancia-se da proposta de Educação Especial expressa na PNEEPEI ao reduzir a educação bilíngue à presença de duas línguas no interior da escola. Assim, apesar de contemplar no plano discursivo a educação bilíngue, os autores destacaram que a proposta de encerramento das escolas especiais para esse público gerou uma série de mobilizações em favor das instituições especializadas. Tais críticas foram contempladas na nova PNEE, ao estabelecer, como possibilidades de serviços, classes e escolas bilíngues, indicando que deverão ser elaboradas propostas de definição de estratégias tanto para implementação quanto para o fortalecimento das instituições existentes (BRASIL, 2020a).

A terceira categoria destaca a centralidade do Atendimento Educacional Especializado (AEE) na PNEEPEI, como justificativa para a construção de um "sistema educacional inclusivo". 
Apesar de alguns autores compreenderem essa justificativa de forma positiva, pois tal proposta se ancora no discurso de igualdade de direitos e oportunidades, como forma de promover a superação da lógica de exclusão, a política de 2008 desconsiderou a trajetória histórica das instituições especializadas na oferta dos serviços ao PAEE. Os autores selecionados ainda indicam que, ao se assumir a concepção de "inclusão total", a Educação Especial ficou centralizada a uma única possibilidade de AEE, desconsiderando-se outras opções de escolha dos beneficiários da modalidade. Nesse sentido, a nova PNEE alterou essa perspectiva de "inclusão total" ao destacar como um de seus princípios a decisão da família ou do educando quanto à alternativa educacional mais adequada, retirando o caráter obrigatório da matrícula dos alunos PAEE do ensino comum na escola regular (BRASIL, 2020a).

Já na quarta categoria, os autores puderam identificar avanços no que se refere ao quantitativo de matrículas dos alunos PAEE nas escolas regulares, comparando-se ao período anterior à PNEEPEI. Assim, ao delimitar que o espaço de escolarização desses alunos deveria ser no ensino comum, reafirmando a Educação Especial como modalidade complementar/suplementar, os autores destacam que a política de 2008 representaria um avanço em relação às anteriormente existentes, ao se opor à educação especializada e substitutiva à Educação Especial. Já a nova PNEE estabelece, como serviços e recursos, espaços físicos para oferta da Educação Especial fora das escolas regulares, permitindo que a modalidade seja ofertada em espaços segregados e especializados (BRASIL, 2020a).

A última categoria destacou como principais críticas dos autores a proposta do retorno do caráter substitutivo da Educação Especial pela previsão da disponibilização de serviços vinculados à modalidade fora do ambiente regular. Ao ter privilegiado a ampliação do atendimento público em detrimento do privado, a PNEEPEI acentuou embates entre diferentes grupos que defendem posicionamentos contrários com relação ao lócus de atendimento dos alunos PAEE. Os autores ainda ressaltaram que a proposta de atualização previa a realização de parcerias público-privadas para oferta da Educação Especial, indo na contramão da proposta da PNEEPEI. Entretanto, a nova política, diferentemente da minuta apresentada em 2018, não indicou explicitamente a realização dessas parcerias com instituições, geralmente filantrópicas/assistenciais, que historicamente ofertaram no País esse tipo de atendimento especializado. Com o argumento de que muitos autores criticavam a disponibilização de uma única forma de atendimento na modalidade da Educação Especial, na nova política foram indicadas 17 possibilidades de serviços, sem citar, contudo, como esses seriam implementados especificamente e se iriam funcionar sob responsabilidade do Estado ou por meio de parcerias público-privadas (BRASIL, 2020a).

Alguns autores ainda apontaram que as críticas feitas por pesquisadores da área sobre a PNEEPEI foram utilizadas como justificativas para que fosse elaborada uma proposta de atualização da política. Esses autores, porém, denunciam a arbitrariedade na qual esse processo foi conduzido, desconsiderando as indicações realizadas pelos pesquisadores e seus grupos de pesquisa ao serem propostas novas diretrizes sem que de fato houvesse articulação e diálogo com o meio acadêmico. É preciso destacar que, após a divulgação da nova política, uma série de manifestações contrárias ao decreto foram formuladas, sob o argumento de que as diretrizes indicadas no documento vão de encontro às orientações internacionais que versam sobre a educação dos alunos PAEE, das quais o Brasil é signatário.

Os pesquisadores da Educação Especial e os grupos de pesquisa de diversas instituições ${ }^{14}$ posicionaram-se contra o decreto, ao reforçarem que tal normativa foi constituída de forma antidemocrática e arbitrária, incentivando que muitos parlamentares constituíssem Projetos de Decreto Legislativo $^{15}$ com o objetivo de sustarem o Decreto no ${ }^{\circ} 10.502 / 20$, que instituiu a nova política. Por outro lado, observam-se manifestações favoráveis ao decreto ${ }^{16}$, despendidas em sua maioria por entidades vinculadas às instituições privadas, filantrópicas e assistenciais que ofertam serviços especializados. A realização deste balanço de produção possibilitou identificar que as principais críticas dos pesquisadores acerca da PNEEPEI foram contempladas por meio das modificações circunscritas na nova política,

\footnotetext{
${ }^{14}$ Manifesto do LEPED em repúdio ao desmonte da Política Nacional de Educação Especial na perspectiva da educação inclusiva (PNEEPEI/2008) (MANTOAN, 2020); Nota de repúdio ao Decreto no 10.502 (ANPED; ABPEE, 2020).

15 Projeto de Decreto Legislativo no 427/20 (BRASIL, 2020b); Projeto de Decreto Legislativo n 429/20 (BRASIL, 2020c); Projeto de Decreto Legislativo n ${ }^{\circ} 437 / 20$ (BRASIL, 2020d).

16 Nota de apoio e esclarecimento sobre o decreto da Política Nacional de Educação Especial (FENEIS, 2020); Posicionamento sobre a Política Nacional de Educação Especial (FENAPAES, 2020).
}

Educação em Revista|Belo Horizonte|v.37|e26361|2021 
como exemplo, a centralidade do AEE como única opção aos alunos PAEE e maior ênfase à educação bilíngue. No entanto, os avanços foram desconsiderados, tais como a concepção de que a Educação Especial é uma modalidade complementar/suplementar, pois, no novo documento, foi indicado que esta modalidade pode ser oferecida de forma substitutiva ao ensino regular.

Considera-se que os textos expressos nas políticas evidenciam "vozes discordantes, em disputa" (SHIROMA; CAMPOS; GARCIA, 2005, p. 431) e que essas disputas não são apenas conceituais, uma vez que estão impregnadas das condições e intenções políticas que marcaram sua produção, expressando, assim, interesses divergentes. Nesse sentido, compreende-se que a nova política reflete embates entre os que defendem a educação inclusiva e o AEE na escola regular e os que desejam a manutenção das escolas e classes especiais na oferta da Educação Especial, em espaços segregados. Portanto, novas pesquisas devem ser desenvolvidas como forma de identificar quais projetos estão em disputa no âmbito do processo de atualização da PNEEPEI, assim como os reais objetivos anunciados e/ou implícitos na versão atualizada da política.

Conclui-se que, embora se reconheçam as limitações impostas pela objetividade requerida no tratamento das informações no presente artigo e pela opção da realização das buscas de trabalhos em bancos de dados específicos, recomendam-se a continuidade e o desenvolvimento de novos estudos dessa natureza, principalmente diante dos desafios apresentados aos pesquisadores da Educação Especial com relação às novas orientações vinculadas no Decreto ${ }^{\circ} 10.502 / 20$. Diante disso, sugere-se que os pesquisadores que tenham interesse em desenvolver balanço de produções com relação à temática da Educação Especial busquem, para além dos bancos de dados utilizados, outras fontes, nacionais e/ou internacionais ${ }^{17}$, que possam apresentar trabalhos, quantitativamente e qualitativamente diferentes dos que foram analisados, na busca por ampliar os debates vinculados à temática brevemente trabalhada neste artigo.

\section{REFERÊNCIAS}

ANPED, Associação Nacional de Pós-Graduação e Pesquisa em Educação; ABPEE, Associação Nacional de Pós-Graduação e Pesquisa em Educação Especial. Nota de repúdio ao Decreto N. ${ }^{\circ} 10.502$. Disponível em:

https://anped.org.br/sites/default/files/images/nota_repudio_anped_abnpee_ee_decreto_n.o_10.502 _final.docx.pdf. Acesso em: 22 out. 2020.

BAPTISTA, Claudio Roberto. Política pública, Educação Especial e escolarização no Brasil. Educ. Pesqui., São Paulo, v. 45, e217423, 2019. Disponível em:

https://www.scielo.br/scielo.php?script=sci_arttext\&pid=S1517-97022019000100407\&lang=pt. Acesso em: 19 set. 2020.

BRASIL. Decreto n ${ }^{\circ}$ 10.502, de 30 de setembro de 2020. Institui a Política Nacional de Educação Especial: Equitativa, Inclusiva e com Aprendizado ao Longo da Vida. Brasília, 2020. Disponível em: http://www.planalto.gov.br/ccivil_03/_ato2019-2022/2020/decreto/D10502.htm. Acesso em: 16 out. 2020.

BRASIL. Política Nacional de Educação Especial na Perspectiva da Educação Inclusiva. Brasília: MEC/SEESP, 2008. Disponível em: http://portal.mec.gov.br/seesp/arquivos/pdf/politica.pdf. Acesso em: 18 set. 2020.

BRASIL. Manual de Orientação: Programa de Implantação de Sala de Recursos Multifuncionais. Brasília: MEC/SEESP. Disponível em: http://portal.mec.gov.br/index.php?option=com_docman\&view=download\&alias=9936-manual-

\footnotetext{
17 A página virtual da Faculdade de Educação da USP apresenta uma listagem de Portais e Bases de Dados de acesso gratuito e de acesso pago. Disponível em: http://www4.fe.usp.br/biblioteca/capacitacao-usuarios/guias-bases-de-dadosfeusp. Acesso em: 24 fev. 2021.
} 
orientacao-programa-implantacao-salas-recursos-multifuncionais\&category_slug=fevereiro-2012pdf\&Itemid=30192. Acesso em: 21 fev. 2021.

BRASIL. Projeto de Decreto Legislativo n ${ }^{\circ}$ 427/20. Câmara dos Deputados. Brasília, 2020b. Disponível em: https://www.camara.leg.br/proposicoesWeb/prop_mostrarintegra;jsessionid=EFE117849DACD0A4 0D16F928A1FC5917. proposicoesWebExterno2? codteor=1933710\&filename $=$ PDL $+427 / 2020$.

Acesso em: 21 out. 2020.

BRASIL. Projeto de Decreto Legislativo no 429/20. Câmara dos Deputados. Brasília, 2020c. Disponível em: https://www.camara.leg.br/proposicoesWeb/prop_mostrarintegra?codteor=1933747\&filename=PDL +429/2020. Acesso em: 20 out. 2020.

BRASIL. Projeto de Decreto Legislativo n 437/20. Senado Federal. Brasília, 2020d. Disponível em: https://legis.senado.leg.br/sdleggetter/documento?dm=8896006\&ts=1601939352001\&disposition=inline. Acesso em: 17 out. 2020 .

BRASIL. Sinopses Estatísticas da Educaşão Superior - Graduação. Instituto Nacional de Estudos e Pesquisas Educacionais Anísio Teixeira. Brasília, 2018. Disponível em:

http://portal.inep.gov.br/web/guest/sinopses-estatisticas-da-educacao-superior. Acesso em: 19 set. 2020.

CASTELO, Rodrigo. O social-liberalismo: uma ideologia neoliberal para a "questão social" no século XXI. Rio de Janeiro: UFRJ/ESS, 2011. Disponível em:

http://www.unirio.br/cchs/ess/Members/rodrigo.castelo/artigos/tese-o-social-liberalismo1/at_download/file. Acesso em: 25 out. 2020.

COLLARES, Cecília A. L.; MOYSÉS, Maria Aparecida Affonso. A transformação do espaço pedagógico em espaço clínico (a patologização da educação). Série Ideias, São Paulo, n. 23, FDE, p. 2531, 1994. Disponível em: http://www.crmariocovas.sp.gov.br/pdf/ideias_23_p025-031_c.pdf. Acesso em: 17 set. 2020.

CORREIA, Gilvane Belem; BAPTISTA, Claudio Roberto. Política Nacional de Educação Especial na perspectiva da educação inclusiva de 2008: quais origens e quais trajetórias? RPGE - Revista on line de Politica e Gestão Educacional, Araraquara, v. 22, n. esp. 2, p. 716-731, dez. 2018. Disponível em: https://periodicos.fclar.unesp.br/rpge/article/view/11905. Acesso em: 22 set. 2020.

DIRETÓRIO NACIONAL DE PERIÓDICOS EM EDUCAÇÃO. Página inicial-Regiões. Gildenir Carolino Santos; Jade Carmine Riciopo; Isabela Doraci C. Machado Xavier (Orgs.). Campinas: BCCL/UNICAMP, 2018. Disponível em: https://sites.google.com/g.unicamp.br/diretorioeduc/p\%C3\%A1gina-inicial. Acesso em: 16 set. 2020.

FENAPAES. Federação Nacional das Associações de Pais e Amigos dos Excepcionais. Posicionamento sobre a Política Nacional de Educação Especial. Disponível em:

http://apaebrasil.org.br/comunicacao/fenapaes-divulga-posicionamento-sobre-a-politica-nacional-deeducacao-especial. Acesso em: 17 out. 2020.

FENEIS. Federação Nacional de Educação e Integração dos Surdos. Nota de apoio e esclarecimento sobre o decreto da Politica Nacional de Educação Especial. Disponível em:

https://www.instagram.com/p/CGOA7R0Jn_3/. Acesso em: 29 out. 2020.

GARBINI, Fernanda Zanette. A in/exclusão e a formação docente: uma discussão a partir dos estudos foucaultianos. Revista Espaço Acadêmico, n. 134, Ano XII, jul. 2012. Disponível em: 
http://periodicos.uem.br/ojs/index.php/EspacoAcademico/article/view/17699/9442. Acesso em: 8 set. 2020 .

GARCIA, Rosalba Maria Cardoso. Disputas conservadoras na política de Educação Especial na perspectiva inclusiva. In: GARCIA, Rosalba Maria Cardoso (Org.). Políticas de Educaşão Especial no Brasil no início do século XXI. Florianópolis: UFSC/CED/NUP, 2017.

GIL, Antonio Carlos. Métodos e Técnicas de Pesquisa Social. 6. ed. São Paulo: Atlas, 2008.

HARLOS, Franco Ezequiel. DENARI, Fátima Elisabeth; ORLANDO, Rosimeire Maria. Análise da estrutura organizacional e conceitual da Educação Especial brasileira (2008-2013). Rev. Bras. Ed. Esp., Marília, v. 20, n. 4, p. 497-512, out./dez. 2014. Disponível em:

https://www.scielo.br/scielo.php?script=sci_arttext\&pid=S1413-65382014000400003. Acesso em: 12 set. 2020 .

KASSAR, Mônica de Carvalho Magalhães. Educação especial na perspectiva da educação inclusiva: desafios da implantação de uma política nacional. Educar em Revista, Curitiba, n. 41, p. 61-79, jul./set. 2011. Disponível em: https://www.scielo.br/scielo.php?script=sci_arttext\&pid=S010440602011000300005. Acesso em: 14 set. 2020.

KASSAR, Mônica de Carvalho Magalhães; REBELO, Andressa Santos; OLIVEIRA, Regina Tereza Cestari de. Embates e disputas na política nacional de Educação Especial brasileira. Revista Educ. Pesqui., São Paulo, v. 45, 2019.

LODI, Ana Claudia Balieiro. Educação bilíngue para surdos e inclusão segundo a Política Nacional de Educação Especial e o Decreto no 5.626/05. Educ. Pesqui., São Paulo, v. 39, n. 1, p. 49-63, jan./mar. 2013. Disponível em: https://www.scielo.br/scielo.php?script=sci_arttext\&pid=S1517-

97022013000100004. Acesso em: 15 set. 2020.

MACHADO, Jardel Pelissari; PAN, Miriam Aparecida Graciano de Souza. Do Nada ao Tudo: políticas públicas e a educação especial brasileira. Educ. Real., Porto Alegre, v. 37, n. 1, p. 273-294, jan./abr. 2012. Disponível em: https://seer.ufrgs.br/educacaoerealidade/article/view/16130/16048. Acesso em: 11 set. 2020.

MANTOAN, Maria Teresa Eglér. Manifesto do LEPED em repúdio ao desmonte da Política Nacional de Educação Especial na perspectiva da educaşão inclusiva (PNEEPEI/2008). Laboratório de Estudos e Pesquisa em Ensino e Diferença da Universidade Estadual de Campinas - Unicamp. Disponível em: https://inclusaoja.files.wordpress.com/2020/10/leped-carta-convocacao.pdf. Acesso em: 24 out. 2020.

MANZINI, Eduardo José. Política de Educação Especial: considerações sobre público-alvo, formação de professores e financiamento. RPGE - Revista on line de Politica e Gestão Educacional, Araraquara, v. 22, n. esp. 2, p. 810-824, dez. 2018. Disponível em:

https://periodicos.fclar.unesp.br/rpge/article/view/11914/7797. Acesso em: 9 set. 2020.

MENDES, Enicéia Gonçalves. A Política de Educação Inclusiva e o Futuro das Instituições Especializadas no Brasil. Arquivos Analíticos de Políticas Educativas, v. 27, n. 22, 2019. Disponível em: https://epaa.asu.edu/ojs/article/download/3167/2217. Acesso em: 19 fev. 2021.

MINAYO, Maria Cecília. S.; SANCHES, Odécio. Quantitativo-Qualitativo: Oposição ou Complementaridade? Cad. Saúde Públ., Rio de Janeiro, v. 9, n. 3, p. 239-262, jul./set. 1993. Disponível em: https://www.scielo.br/pdf/csp/v9n3/02.pdf. Acesso em: 14 fev. 2021. 
MOCHEUTI, Karina Nonato. Balanço de produção sobre aprendizagem cooperativa e educação superior. In: REUNIÃO NACIONAL DA ANPED, 38., 2017, São Luís. Anais [...]. São Luís: UFMA, 2017. Disponível em:

http://38reuniao.anped.org.br/sites/default/files/resources/programacao/poster_38anped_2017_GT 11_520.pdf. Acesso em: 16 fev. 2021.

NABUCO, Maria Eugênia. Práticas institucionais e inclusão escolar. Cadernos de Pesquisa, v. 40, n. 139, p. 63-74, jan./abr. 2010. Disponível em:

https://www.scielo.br/scielo.php?script=sci_arttext\&pid=S0100-15742010000100004. Acesso em: 14 set. 2020 .

NEVES, Libéria Rodrigues; RAHME, Mônica Maria Farid; FERREIRA, Carla Mercês da Rocha Jatobá. Política de Educação Especial e os desafios de uma Perspectiva Inclusiva. Educação \& Realidade, Porto Alegre, v. 44, n. 1, e84853, 2019. Disponível em:

https://seer.ufrgs.br/educacaoerealidade/article/view/84853. Acesso em: 16 set. 2020.

PINTASSILGO, Joaquim; BEATO, Carlos. Balanço da produção recente no campo da História das Disciplinas Escolares: o exemplo das teses de doutoramento (Portugal, 2005-2015). Cadernos de História da Educaşão, v. 16, n. 1, p. 45-63, 27 abr. 2017. Disponível em:

http://www.seer.ufu.br/index.php/che/article/view/38238. Acesso em: 15 fev. 2021.

RISTOFF, Dilvo. Educação superior no Brasil: 10 anos pós-LDB: da expansão à democratização. In: BITTAR, Mariluce; OLIVEIRA, João F. de; MOROSINI, M. Marília (Orgs.). Educaşão Superior no Brasil: 10 anos pós LDB. Brasília: INEP, 2008, p. 39-50. Disponível em:

http://portal.inep.gov.br/informacao-da-publicacao/-

/asset_publisher/6JYIsGMAMkW1/document/id/492421. Acesso em: 23 set. 2020.

RODRIGUES, Eliane de Oliveira; RAMPELOTTO, Elisane Maria. Gestão democrática e luta por reconhecimento na educação de surdos. Rev. Gest. Aval. Educ., Santa Maria, v. 3, n. 5, jan./jun. 2014. Disponível em: https://periodicos.ufsm.br/index.php/regae/article/view/13425/pdf. Acesso em: 27 set. 2020 .

SANTOS, Kátia Silva; BAPTISTA, Claudio Roberto. Novos 'referenciais' cognitivos e normativos para a Política Nacional de Educação Especial no Brasil. Práxis Educacional, Vitória da Conquista, v. 10, n. 16, p. 15-33, jan./jun. 2014. Disponível em: https://core.ac.uk/download/pdf/236650507.pdf. Acesso em: 29 set. 2020.

SENNA, Manoella; SANTOS, Mônica Pereira dos; LEMOS, Lidiane Moraes Buechen. A participação da sociedade e o caso da Política Nacional de Educação Especial na Perspectiva da Educação Inclusiva: refletindo sobre a formação de professores. Revista Aleph., n. 34, jul. 2020. Disponível em: https://periodicos.uff.br/revistaleph/article/view/41437/25233. Acesso em: 14 set. 2020.

SHIMITE, Amabriane da Silva Oliveira; SILVA, Nilson Rogério da. A proposta de atualização da Política Nacional de Educação Especial em relação à inclusão de alunos com deficiência no Ensino superior. Educação, Psicologia e Interfaces, v. 3, Dossiê Inclusão e Diversidade, p. 8-22, 2019. Disponível em: https://educacaoepsicologia.emnuvens.com.br/edupsi/article/view/191. Acesso em: 16 set. 2020.

SHIROMA, Eneida O.; CAMPOS, Roselane F.; GARCIA, Rosalba M. C. Decifrar textos para compreender a política: subsídios teórico-metodológicos para análise de documentos. In: Revista Perspectiva, Florianópolis: NUP; UFSC, v. 23, p. 427-446, 2005. Disponível em: https://periodicos.ufsc.br/index.php/perspectiva/article/view/9769. Acesso em: 7 jan. 2020. 
SILVA, Régis Henrique dos Reis. Balanço das dissertações e teses em educação especial e educação inclusiva desenvolvidas nos programas de pós-graduação em educação no Brasil. Rev. Bras. Ed. Esp., Marília, v. 24, n. 4, p. 601-618, out./dez. 2018. Disponível em:

https://www.scielo.br/scielo.php?script=sci_abstract\&pid=S1413-

65382018000400601\&lng=pt\&nrm=iso. Acesso em: 15 fev. 2021.

SILVA, César Augusto de Assis; ASSÊNSIO, Cibele Barbalho. Setembro Azul: mobilização política nacional a favor das escolas bilíngues para surdos. Ponto Urbe [Online], n. 9, p. 01-10. 2011. Disponível em: https:// https://journals.openedition.org/pontourbe/1966?lang=en. Acesso em: 27 set. 2020.

SILVA, Kelly Cristina dos Santos; ANGELUCCI, Carla Biancha. A lógica medicalizante nas políticas públicas de educação. Revista Educação Especial, Santa Maria, v. 31, n. 62, p. 683-696, jul./set. 2018. Disponível em: https://periodicos.ufsm.br/educacaoespecial/article/view/29132. Acesso em: 29 set. 2020.

SILVA, Lázara Cristina da; SOUZA, Vilma Aparecida de; FALEIRO, Wender. Uma década da Política Nacional de Educação Especial na Perspectiva da Educação Inclusiva: do ideal ao possível. RPGE Revista on line de Política e Gestão Educacional, Araraquara, v. 22, n. esp. 2, p. 732-747, dez. 2018.

Disponível em: https://periodicos.fclar.unesp.br/rpge/article/view/11906. Acesso em: 19 set. 2020.

SILVA, Régis Henrique dos Reis; MACHADO, Robson; SILVA, Ribamar Nogueira da. Golpe de 2016 e a educação no Brasil: implicações nas políticas de educação especial na perspectiva da educação inclusiva. Revista HISTEDBR On-line, Campinas, v. 19, p. 1-23, 2019. Disponível em: https://periodicos.sbu.unicamp.br/ojs/index.php/histedbr/article/view/8655755. Acesso em: 7 jan. 2020

SILVEIRA, Andréa Pereira; COSTA, Chayenne Amã Perez Santos da. Política Nacional de Educação Especial na Perspectiva da educação inclusiva: diretrizes para alunos surdos. In: LOBATO, Huber Kline Guedes; SILVA, Lucival Fabio Rodrigues da; FIGUEIREDO, Daiane Pinheiro (Orgs.). Diálogos sobre inclusão escolar e ensino aprendizagem da Libras e Lingua Portuguesa como segunda língua para surdos. Belém: UFPA, 2016, p. 129-138. Disponível em:

https://livroaberto.ufpa.br/jspui/bitstream/prefix/519/1/Livro_DialogosInclusaoEscolar.pdf\#page= 129. Acesso em: 26 set. 2020.

ULLRICH, Wladimir Brasil. Política de Educação Especial: sobre ambivalência, tensão e indeterminação. Educação \& Realidade, Porto Alegre, v. 44, n. 1, e84860, 2019. Disponível em: https://seer.ufrgs.br/educacaoerealidade/article/view/84860. Acesso em: 24 set. 2020.

Submetido: $20 / 11 / 2020$

Aprovado: $07 / 07 / 2021$ 